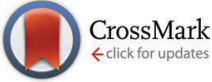

Cite this: New J. Chem., 2016, 40, 5797

Received (in Victoria, Australia) 22nd November 2015 Accepted 21st February 2016 DOI: 10.1039/c5nj03301b

www.rsc.org/njc

\title{
Photophysical and photochemical studies of tricarbonyl rhenium( (I) N-heterocyclic carbene complexes containing azide and triazolate ligands $\dagger$
}

\author{
Peter V. Simpson, ${ }^{a}$ Brian W. Skelton, ${ }^{b}$ Paolo Raiteri ${ }^{\mathrm{a}}$ and Massimiliano Massi*a
}

\begin{abstract}
Rhenium(I) N-heterocyclic carbene $(\mathrm{NHC})$ complexes of the type fac- $\left[\operatorname{Re}(\mathrm{CO})_{3}(\mathrm{NHC}) \mathrm{L}\right]$ with either azide or triazolate ancillary ligands $\mathbf{L}$ and pyridyl or pyrimidyl substituted imidazolyl units have been prepared and structurally characterised, and their photophysical and photochemical properties studied. All of the complexes exhibit phosphorescent emission from triplet metal-to-ligand ( $\left.{ }^{3} M C L T\right)$ excited states, typical of tricarbonyl $\operatorname{Re}($ I) complexes, with the triazolate bound complexes having higher quantum yields and longer decay lifetimes compared to the azide bound complexes. The complexes containing pyridyl substituted imidazolyl units are photoreactive when dissolved in acetonitrile and undergo photochemical $\mathrm{CO}$ dissociation, the rate of which is significantly greater in the azide cf. triazolate complex. The photochemical mechanism of the azide/pyridyl complex was analysed and appears to give the same products, albeit with different ratios, to previously reported complexes where $\mathbf{L}$ is a halide. A reaction mechanism is proposed.
\end{abstract}

\section{Introduction}

Rhenium(I) complexes of the type $f a c-\left[\operatorname{Re}(\mathrm{CO})_{3}(\operatorname{diim}) \mathbf{L}\right]^{0 /+}$, where diim represents a $\pi$-conjugated diimine ligand such as $2,2^{\prime}$-bipyridine (bpy) or 1,10-phenanthroline (phen) and $\mathbf{L}$ is a monodentate anionic or neutral ancillary ligand, have been extensively studied due to their rich photophysical properties that give rise to phosphorescent decay typically from their lowest lying triplet metal-to-ligand charge transfer excited state $\left({ }^{3} \mathrm{MLCT}\right) \cdot{ }^{1-3}$ The emission from these excited states, which often displays relatively high quantum yields and long excited state lifetimes, can be fine tuned by judicious variation of the diim and ancillary ligands, making this class of compounds suitable for many applications including light emitting devices ${ }^{4,5}$ and biological labels. ${ }^{6-8}$

Although complexes based on diim ligands have been thoroughly investigated, analogous complexes of the type fac$\left[\operatorname{Re}(\mathrm{CO})_{3}(\mathrm{NHC}) \mathbf{L}\right]^{0 /+}$, where NHC represents a bidentate N-heterocyclic carbene ligand, which binds the metal through an imine type $\mathrm{N}$ atom and the carbene $\mathrm{C}$ atom, have been considerably less

\footnotetext{
${ }^{a}$ Nanochemistry Research Institute - Department of Chemistry, Curtin University, Kent Street, Bentley 6102 WA, Australia. E-mail: m.massi@curtin.edu.au

${ }^{b}$ Centre for Microscopy, Characterisation and Analysis,

University of Western Australia, Crawley 6009 WA, Australia

$\dagger$ Electronic supplementary information (ESI) available. CCDC 1431845-1431848. For ESI and crystallographic data in CIF or other electronic format see DOI: 10.1039/c5nj03301b
}

studied despite their ubiquity in inorganic chemistry. Nevertheless, complexes possessing NHC ligands bound to $\mathrm{Ru}(\mathrm{II})$, $\mathrm{Pt}(\mathrm{II}), \operatorname{Ir}(\mathrm{III})$ and $\mathrm{Au}(\mathrm{I})^{8-12}$ (just to name a few) display rich luminescent properties and so their effect on the photophysical properties of $\operatorname{Re}(\mathrm{I})$ complexes is of great interest. Along those lines, we $\mathrm{e}^{13-15}$ and others ${ }^{16,17}$ have investigated these type of complexes, where the NHC is substituted in the 1-position with different imine type $\mathrm{N}$ donors that bind to the rhenium and thus change their photophysical properties. We have found that if the NHC contains a pyridyl as the $\mathrm{N}$ donor, the complex can exhibit photochemical CO dissociation in acetonitrile solution to form a tricarbonyl acetonitrile solvated complex and two different dicarbonyl complexes. While we have modified the $\mathrm{N}$ donor group to pyrimidyl, quinolyl, and quinoxyl to probe the scope of the photochemistry, we have found that only the pyridyl containing complexes are photoactive. These photoactive rhenium complexes could be of potential benefit in the area of photoinducible CO-releasing molecules (photoCORMs), whereby bioactive $\mathrm{CO}$ is released from the metal centre in a spatially and temporally controlled manner. ${ }^{18-21}$

We have recently become interested in the coordination of azide ligands to metal NHC complexes and their associated reactivity toward alkynes in a 1,3-diploar cycloaddition reaction. This area of chemistry has been extensively investigated by the group of Veige, ${ }^{22-25}$ who have studied the reaction of metal azides and metal alkynyl complexes, and others who have investigated the reactions of metal azides with organic alkynes. ${ }^{26-28}$ In the 
context of CORMs, the inclusion of a reactive azido ligand into the rhenium complex could be used to prepare and study photoactive CO-releasers bound to biological molecules, through an in situ click reaction with alkynyl functionalised biomolecules, without the need to add any additional catalysts such as copper(II) sulfate and ascorbate. Thus, in this study, we aim to expand our knowledge of complexes of the type $f a c-\left[\mathrm{Re}(\mathrm{CO})_{3}(\mathrm{NHC}) \mathbf{L}\right]$ by modifying the $\mathbf{L}$ ancillary ligand from exclusively halide $\left(\mathrm{Cl}^{-}\right.$and $\left.\mathrm{Br}^{-}\right)$to azide, and then reacted the metal azide with the model alkyne dimethyl acetylenedicarboxylate to form a triazolate ligand via the 1,3-diplor cycloaddition. Two sets of complexes containing pyridyl and pyrimidyl substituents on the NHC ligands as well as azide and triazolate ancillary ligands have been prepared, and their photophysical and photochemical properties studied.

\section{Results and discussion}

\section{Synthesis and characterisation}

Treatment of 1a and 1b with silver triflate in acetone and subsequent stirring over an excess of sodium azide led to the formation of $\mathbf{2 a}$ and $\mathbf{2 b}$ (Scheme 1), which were isolated in yields of 59 and $68 \%$, respectively. The two complexes are soluble in most common organic solvents including dichloromethane, chloroform, acetone, methanol, dimethylsulfoxide, and dimethylformamide, and even exhibit moderate solubility in diethyl ether. Despite the excellent solubility of $\mathbf{2 a}$, the complex is rather unstable toward both heat and light, and care must be taken during isolation. In contrast, complex $\mathbf{2 b}$ is stable toward both heat and light, with no decomposition observed during isolation. A strong azide stretch is observed in the IR spectra of $\mathbf{2 a}$ and $\mathbf{2 b}$ at 2047 and $2056 \mathrm{~cm}^{-1}$, respectively, while the facially arranged CO ligands are seen as three distinct stretches at 2010, 1916, and $1869 \mathrm{~cm}^{-1}$ for $2 \mathrm{a}$; and two stretches at 2007 and $1889 \mathrm{~cm}^{-1}$ for $2 \mathbf{b}$, due to the overlap of the $\mathrm{A}^{\prime}(2)$ and $\mathrm{A}^{\prime \prime}$ modes into a single broad band. Analysis of the ${ }^{1} \mathrm{H}$ NMR spectra of $\mathbf{2 a}$ and $\mathbf{2} \mathbf{b}$ reveals that, in a similar fashion to the parent compounds $\mathbf{1 a}$ and $\mathbf{1 b}$, the corresponding azide complexes also exhibit a restricted rotation of the mesityl group around the $\mathrm{C}-\mathrm{N}$ bond, as evidenced by the three singlets observed for the non-equivalent mesityl methyl environments. ${ }^{15}$ Additionally, the presence of three signals are observed in the ${ }^{13} \mathrm{C}$ NMR spectra at ca. 197, 196, and $192 \mathrm{ppm}$ for the three CO groups, as expected for the presence of three different ligands coordinated trans to them.

In the presence of the alkyne dimethyl acetylenedicarboxylate (DMAD), the azide complexes $\mathbf{2 a}$ and $\mathbf{2 b}$ undergo a 1,3-dipolar cycloaddition that converts the azide ligand to an anionic triazolate ligand (Scheme 1). Specifically, addition of an excess DMAD to an acetone solutions of $\mathbf{2} \mathbf{a}$ and $\mathbf{2 b}$, followed by stirring overnight at room temperature (for $\mathbf{2 a}$ ) or reflux (for $\mathbf{2 b}$ ) led to the formation of $\mathbf{3 a}$ and $\mathbf{3} \mathbf{b}$, which were isolated as off-white solids in yields of 52 and $63 \%$, respectively. Complexes $3 a$ and 3b display drastically reduced solubility in organic solvents cf. $\mathbf{2} \mathbf{a}$ and $\mathbf{2} \mathbf{b}$, being moderately soluble in acetone, methanol, dimethylsulfoxide, and dimethylformamide. The disappearance of the azide stretch in the IR spectra of $\mathbf{3} \mathbf{a}$ and $\mathbf{3} \mathbf{b}$ confirms the consumption of the azide precursors, while the presence of three stretches in the $2020-1870 \mathrm{~cm}^{-1}$ region is consistent for the facially arranged CO ligands. The ${ }^{1} \mathrm{H}$ NMR spectra of $3 \mathbf{a}$ and $3 \mathbf{b}$ is not straightforward: for every signal in the ${ }^{1} \mathrm{H}$ NMR spectra a small neighbouring peak is observed, with the exception of the triazolate methyl singlet, which instead shows two smaller signals of half integration. Analysis of the ${ }^{1} \mathrm{H}$ NMR spectra reveals two isomers in a ratio of $c a$. $1: 0.18$, which are ascribed to the coordination of the triazolate ligand via the $\mathrm{N}(2)$ and $\mathrm{N}(1)$ nitrogen atoms, respectively. These isomers could not be separated. As demonstrated by Veige and co-workers, the cycloaddition reaction between gold or platinum azides and gold alkynyl complexes will form N(1) coordinated triazolates. ${ }^{23,24}$ In the case of octahedral metal complexes, however, steric interactions between the ligands and the newly formed triazolate will be such that the kinetically formed $\mathrm{N}(1)$ coordinated triazolate will favour isomerisation to the $\mathrm{N}(2)$ form. Although single crystals of $\mathbf{3 a}$ and $\mathbf{3} \mathbf{b}$ could be obtained (see X-ray studies), we could not produce a sufficient quantity of crystals that would allow for a detailed NMR study of the interconversion of the triazolate ligand to be performed. Interestingly, coordination of a triazolate ligand via the $\mathrm{N}(1)$ nitrogen has only been reported twice before in the ruthenium acetylacetonate (acac) complexes 4-6 $6^{29}$ and also in hexanuclear rhenium chalcogenide cluster 8, see below in Fig. $1 .^{30}$ In these cases, where two methyl esters are on the backbone of the N(1) bound triazolate ligand, the methyl group are seen as two separate singlets in the ${ }^{1} \mathrm{H}$ NMR spectra in a similar fashion to $\mathbf{3 a}$ and $\mathbf{3 b}$. In the case of the ruthenium acetylacetonate $\left(\mathrm{acac}^{-}\right)$complexes, the formation of the $\mathrm{N}(1) c f . \mathrm{N}(2)$ bound triazole was heavily dependent on the
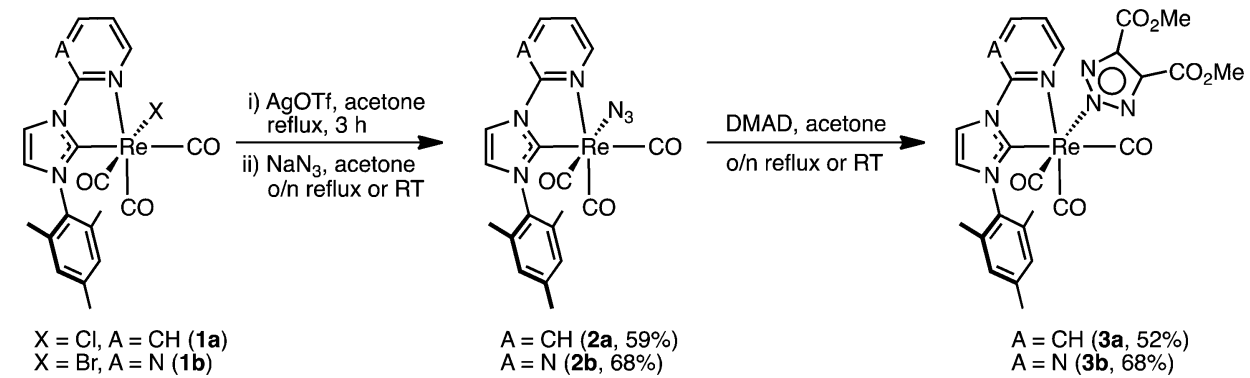

$A=\mathrm{CH}(3 \mathrm{a}, 52 \%)$
$\mathrm{A}=\mathrm{N}(3 \mathbf{b}, 68 \%)$

Scheme 1 Synthesis of azido and triazolate complexes via a 1,3-diploar cycloaddition. 


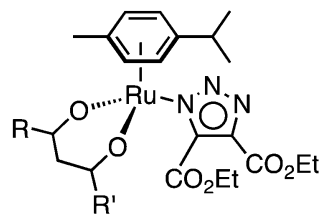

$\mathrm{R}=\mathrm{Me}, \mathrm{R}^{\prime}=\mathrm{Me}(\mathbf{5})$

$\mathrm{R}=\mathrm{Me}, \mathrm{R}^{\prime}=\mathrm{Ph}(\mathbf{6})$

$\mathrm{R}=\mathrm{Ph}, \mathrm{R}^{\prime}=\mathrm{Ph}(\mathbf{7})$

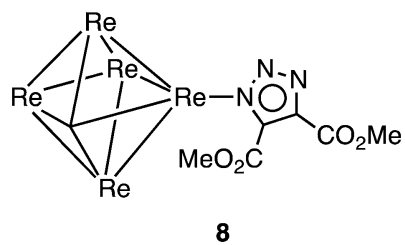

Fig. 1 Previously reported cases of triazolate ligands bound to a metal centre through the N(1) nitrogen atoms. The phosphorous, selenium, carbon, and hydrogen atoms of the cluster core have been removed for clarity.

substituents on the triazole and acac $^{-}$ligands, with the complexes 5-7 being formed as sole isomer formed in the reaction. Rhenium cluster 8 , however, was formed in only $c a$. $2 \%$ relative to the $\mathrm{N}(2)$ bound major isomer.

\section{X-Ray structural investigation}

Single crystals suitable for X-ray diffraction studies were grown for each of the complexes (see Experimental section for crystal growth conditions), projections of which can be seen in Fig. 2. The structures are consistent with the proposed formulations of the complexes, with each possessing facially arranged tricarbonyl ligands. In all cases, the plane of the mesityl substituent is oriented $c a .90^{\circ}$ with respect to the imidazolyl plane. A point of interest within the four structures is the angle between the planes of the imidazole and pyridyl/pyrimidyl rings; while the azido complex 2a is strained in this respect with an interplanar angle of $11.4^{\circ}$, the imidazole unit in complex $\mathbf{2 b}$ is almost completely coplanar with the pyrimidyl group, with an interplanar angle of just $1.6^{\circ}$. This seems to be due to the orientation of the azide ligand; in $2 \mathrm{a}$ the azide points back toward the carbene, thus bringing it close to one of the methyl groups on the mesityl substituent. The azido ligand in $\mathbf{2 b}$, however, is directed away from the carbene and has no effect on the imidazolyl-pyrimidyl interplanar angle. The rhenium-carbene carbon distances are 2.123(4) and 2.118(5) $\AA$ for $2 \mathbf{a}$ and $2 \mathbf{b}$, respectively, indicating that there are no significant differences in the donating ability of the two carbene ligands.

In the structures of $\mathbf{3 a}$ and $\mathbf{3 b}$, the triazole ligand is coordinated at the N(2) position, with Re-N distances of 2.172(2) and $2.1657(18) \AA$, respectively. The nitrogen atoms in the triazole are now slightly further apart from the mesityl methyl group than in the case of $2 \mathbf{a}$ and $\mathbf{2} \mathbf{b}$, with distances ranging from 3.76-3.85 and 3.60-3.85 $\AA$ for $3 \mathbf{a}$ and $3 \mathbf{b}$, respectively. The differences between $\mathbf{3 a}$ and $\mathbf{3} \mathbf{b}$ can be explained by two factors: the smaller interplanar angle between the triazolate and the Re-C(2)-N(42)-C(101)-C(102) coordination planes in $\mathbf{3 b}$ cf. 3a of $52.15^{\circ}$ and $57.75^{\circ}$, respectively; and the slightly more twisted nature of the mesityl ligand in $\mathbf{3 b} \mathbf{b}$, which brings the mesityl methyl group closer to the triazolate. A close examination of the mesityl methyl signals in the ${ }^{1} \mathrm{H}$ NMR spectra of $\mathbf{3 a}$ and $\mathbf{3 b}$ suggests that these slight differences are maintained in solution, presumably due to the rigidity of these complexes. The aromatic nature of the triazolate ring causes an upfield chemical shift in the ${ }^{1} \mathrm{H}$ NMR spectra of $3 \mathbf{a}$ and $3 \mathbf{b}$, with the closer contacts in $\mathbf{3 b}$ leading to a slightly more upfield shift of $1.47 \mathrm{ppm}$, compared to $1.56 \mathrm{ppm}$ for $3 \mathrm{a}$.

\section{Photophysical investigation}

The photophysical data of all the complexes in dilute dichloromethane solutions are summarised in Table 1, with all absorption and emissions profiles shown in Fig. 3 (see ESI, $\dagger$ Fig. S1 for excitation spectra). The absorption spectra of $\mathbf{2 a} \mathbf{a}, \mathbf{b}$ and $\mathbf{3 a}, \mathbf{b}$ exhibit high-energy bands from $c a$. 250-300 $\mathrm{nm}$, and lower energy bands of relatively smaller molar absorptivity above $300 \mathrm{~nm}$. The higher energy bands are associated with ligand-centred (LC) $\pi \rightarrow \pi^{*}$ transitions within the NHC and, in the case of $\mathbf{3 a}$ and $\mathbf{3 b}$, the triazolate ligands. On the other hand, the lower energy bands are assigned to an admixture of MLCT ( $\mathrm{Re} \rightarrow \mathrm{NHC}$ ) and ligandto-ligand (azide/triazolate $\rightarrow$ NHC; LLCT) charge transfer transitions, as previously described for similar complexes. ${ }^{13-15} \mathrm{~A}$ slight red-shift in the mixed MLCT/LLCT transitions of $\mathbf{2 b} c f .2 \mathbf{2}$ and 3b $c f$. $3 \mathbf{a}$ of 5 and $6 \mathrm{~nm}$, respectively, is attributed to the more electron deficient pyrimidyl- versus pyridyl-substituted NHC ligands.
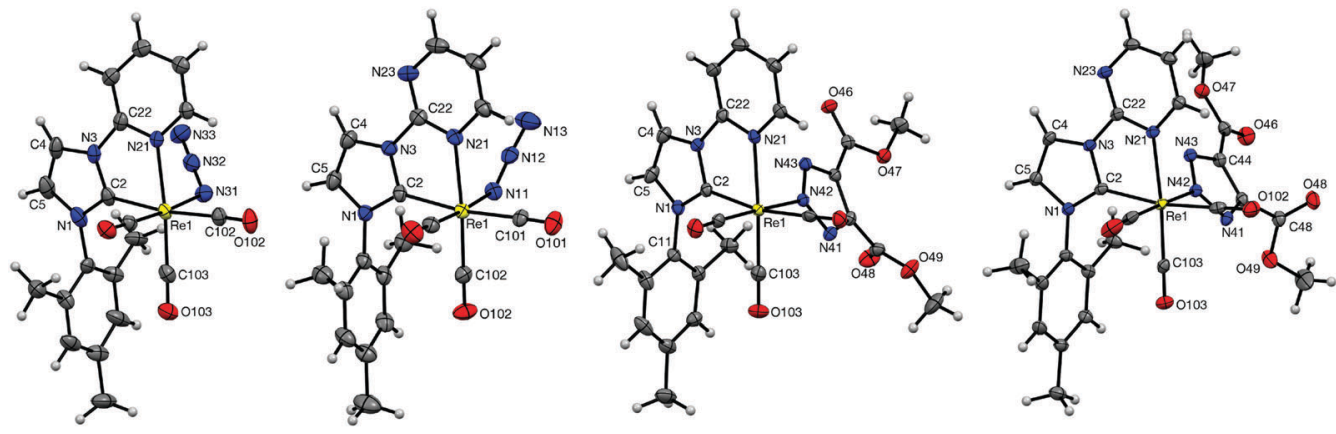

Fig. 2 X-Ray structures of the complexes $\mathbf{2} \mathbf{a}, \mathbf{b}$ and $\mathbf{3 a} \mathbf{a} \mathbf{b}$. Disordered groups and solvents present in the unit cell have been omitted for clarity. Ellipsoids are displayed at the $50 \%$ probability level. 
Table 1 Photophysical properties of the complexes from diluted dichloromethane solutions $\left(\mathrm{ca} .10^{-5} \mathrm{M}\right)$

\begin{tabular}{|c|c|c|c|c|c|c|c|c|}
\hline & \multirow[b]{2}{*}{$\lambda_{\mathrm{abs}}(\mathrm{nm})\left(10^{4} \varepsilon\left(\mathrm{cm}^{-1} \mathrm{M}^{-1}\right)\right)$} & \multicolumn{5}{|c|}{ Emission (room temperature) } & \multicolumn{2}{|c|}{ Emission $(77 \mathrm{~K})$} \\
\hline Complex & & $\lambda_{\mathrm{em}}(\mathrm{nm})$ & $\tau^{a}(\mathrm{~ns})$ & $\tau^{b}(\mathrm{~ns})$ & $\phi^{a, c}$ & $\phi^{b, c}$ & $\lambda_{\mathrm{em}}(\mathrm{nm})$ & $\tau(\mu \mathrm{s})$ \\
\hline $2 \mathbf{a}$ & $228(3.31), 362(0.42)$ & 564 & 45 & 109 & 0.007 & 0.018 & 495 & $0.8(23 \%), 4.4(77 \%)$ \\
\hline $3 \mathbf{a}$ & $273(1.51), 330(0.65)$ & 504 & 79 & 216 & 0.011 & 0.036 & 458 & $0.9(12 \%), 4.1(88 \%)$ \\
\hline $3 \mathbf{b}$ & $274(9.55), 336(0.57)$ & 559 & 115 & 635 & 0.0055 & 0.024 & 488 & $3.2(21 \%), 8.0(79 \%)$ \\
\hline
\end{tabular}
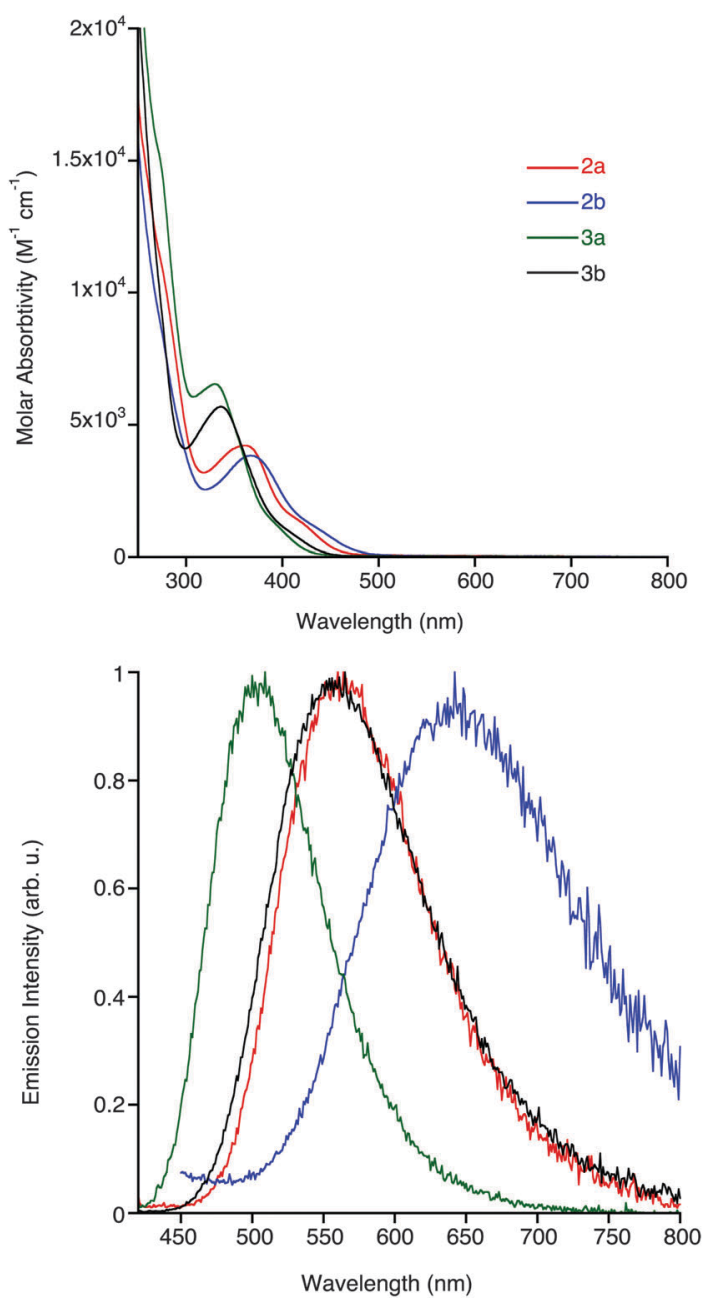

Fig. 3 Experimental absorption (top) and emission profiles (bottom) of the complexes from dilute dichloromethane solutions (ca. $10^{-5} \mathrm{M}$ ) at room temperature. The emission profiles were obtained by exciting the complexes to their lowest energy $\lambda_{\text {abs. }}$. The same colour coding (inset) is used between the absorption and emission profiles.

Comparison of the maxima of the lower-energy bands in the four complexes shows a decrease of ca. $30 \mathrm{~nm}$ going from azide- to triazolate-ligated species, which can be attributed to the electron-withdrawing nature of the triazolate ligand that serves to lower the energy of the HOMO, which is located primarily on the metal centre.

The emission profiles of the four complexes show broad and structureless bands located at 500-650 nm, which are common for emissive states of MLCT/LLCT character. Complexes 2a and $\mathbf{2 b}$, possessing the azide ancillary ligands, have lower energy emissions than $\mathbf{3 a}$ and $\mathbf{3} \mathbf{b}$ due to the electron-donating ability of the azide ligand raising the energy of the HOMO. There is a general red-shift in the emission from the pyrimidyl-based complexes relative to their pyridyl-based analogues, which is particularly prevalent for the azide complexes $\mathbf{2 a}$ and $\mathbf{2 b}$, where the $\lambda_{\mathrm{em}}$ are 564 and $645 \mathrm{~nm}$, respectively. This difference is smaller in the triazolate containing complexes, where the $\lambda_{\mathrm{em}}$ for $\mathbf{3 a}$ and $\mathbf{3 b}$ are located at 504 and $559 \mathrm{~nm}$, respectively. The emission wavelengths of $\mathbf{2} \mathbf{a}, \mathbf{b}$ and $\mathbf{3} \mathbf{a}, \mathbf{b}$ are significantly different than previously reported analogous complexes containing halide ancillary ligands, ${ }^{15}$ which suggests that the presence of either an azide or triazolate ligand strongly influences the energy of the excited states. The lifetime decays $(\tau)$ of the complexes are monoexponential in nature and range from 8 to $115 \mathrm{~ns}$, which then elongate after degassing; a similar trend is observed for the quantum yields, suggestive of an emissive state of triplet multiplicity $\left({ }^{3} \mathrm{MLCT} /{ }^{3} \mathrm{LLCT}\right) .{ }^{31,32}$ The marked differences in the lifetime decays of $\mathbf{2} \mathbf{b}$ can be explained, in part, by the energy gap law. Complex $\mathbf{2 b}$, containing both the HOMO-raising azide ligand and the LUMO-lowering pyrimidyl substituent, has a relatively small HOMO-LUMO gap and therefore a high non-radiative decay constant $\left(k_{\mathrm{nr}}\right)$ in the order of $10^{8} \mathrm{~s}^{-1}$, leading to relatively fast decay lifetimes and a quantum yield $c a .0 .1 \%$. Both triazolatecontaining complexes have higher decay lifetimes and quantum yields that their azide-containing analogues. In a frozen matrix at $77 \mathrm{~K}$ (see ESI, $\dagger$ Fig. S2) all complexes display blue-shifted emission due to the rigidochromic effect, with decay lifetimes ranging from $0.5-8 \mu \mathrm{s}$.

\section{Computational studies}

To validate the interpretation of the photophysical data, timedependent density functional theory (TD-DFT; see Fig. 5 and ESI, $\dagger$ for orbital contours and table of calculated transitions) was used to simulate the energetics and absorption spectra of the four complexes. The structures were relaxed in dichloromethane and found to be consistent with the structures obtained from X-ray diffraction. The calculations indicate that the lower energy transitions involve the HOMO $-n(n=0,1)$ orbitals and the LUMO+m $(m=0,1)$ orbitals for $\mathbf{2 a}$ and $\mathbf{2 b}$; and from the HOMO $-n(n=0,1,2)$ orbitals to the LUMO $+m(m=0,1)$ orbitals for $\mathbf{3 a}$ and $\mathbf{3 b}$. In agreement with the band assignment proposed above, the orbital contours show that these transitions are of MLCT nature that are partially mixed with LLCT character, a representative of which is shown in Fig. 4 for complex $2 \mathbf{a}$. 

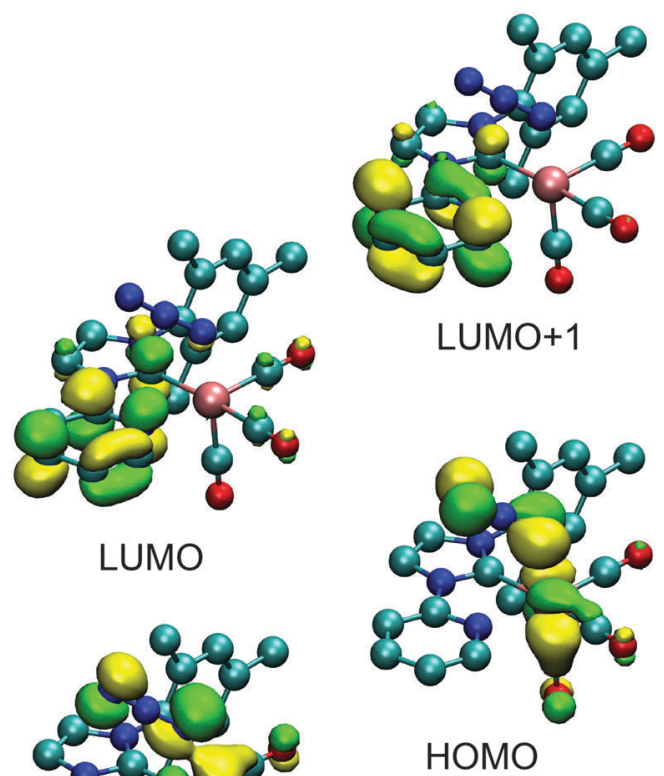

HOMO-1

Fig. 4 Selected orbital representations for $\mathbf{2 a}$

The higher energy transitions in the region of $250-300 \mathrm{~nm}$ are calculated as being LC $\pi \rightarrow \pi^{*}$ in nature.

\section{Photochemical investigation}

The photochemical properties of the complexes as solutions in $\mathrm{CD}_{3} \mathrm{CN}$ were assessed using ${ }^{1} \mathrm{H}$ NMR spectroscopy with an irradiation wavelength of $365 \mathrm{~nm}$, which corresponds to excitation into the MLCT/LLCT manifold. It was found that while the complexes with pyridyl-functionalised carbene ligands were photoactive, those containing pyrimidyl groups were photostable. This observation matches previously reported trends for rhenium complexes of carbene ligands. ${ }^{14,15}$ The ${ }^{1} \mathrm{H}$ NMR spectra of 2a during photolysis over 8 hours is shown in Fig. 5 . Examination of signals associated with $\mathrm{N6}^{\prime}$ shows that, after one hour, complex $2 \mathrm{a}$ has disappeared and two new species of low and high integration have been formed at 8.63 and $8.71 \mathrm{ppm}$, respectively. The signal at 8.63 has the same integration as another new signal at $9.44 \mathrm{ppm}$, which is characteristic of the $\mathrm{H} 2$ hydrogen in an imidazolium salt and suggests that these signals are associated with the formation of 1-pyridyl-3-mesitylimidazolium azide. It seems probable that the $\mathrm{H} 2$ hydrogen atom of the imidazolium salt arises from adventitious water present in the deuterated solvent. Over the course of the photolysis, the signals associated with the imidazolium salt continue to grow, while the intensity of the signal at $8.71 \mathrm{ppm}$ increases for 3 or 4 hours, then decreases to zero by 7 hours. Close examination also shows that after 4 hours, a new species at $8.85 \mathrm{ppm}$ begins to grow. Although the chemical shift of this new photoproduct is the same as for $\mathbf{2 a}$, it is clearly a different compound as is evident by the disappearance of $\mathbf{2 a}$ after only

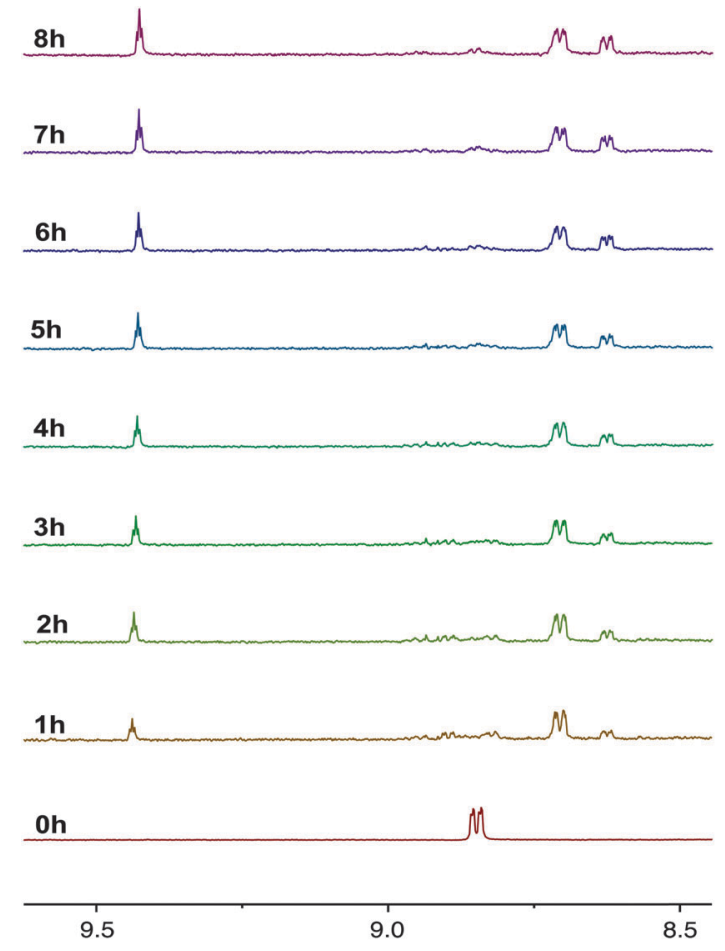

Fig. $5{ }^{1} \mathrm{H}$ NMR progression of the photolysis of $2 \mathbf{a}$ in deuterated acetonitrile solutions. The photolysis was performed by irradiating the sample at $365 \mathrm{~nm}$ over a period of $8 \mathrm{~h}$.

one hour. The formation of unidentifiable decomposition products was observed from 8.87-8.98 ppm.

The rapid photolysis of 2 a shown in Fig. 5 does not give an indication of what occurs in the early stages of the photoreaction. Therefore, the experiment was carefully repeated for the initial hour to see if any intermediates were formed that might shed some light on the reaction pathway. The results were illuminating, and are shown in Fig. 6. After one minute of photolysis, the imidazolium salt can just be observed as signals at 9.44 and $8.63 \mathrm{ppm}$, and continues to slowly form during the entire 60 minutes. The next products to form are first observed after 5 minutes photolysis at 8.81 and $8.70 \mathrm{ppm}$; the former growing very slowly and the latter at 8.71 growing to be the major product over the course of the hour.

Although the NMR photolysis of 2 a shows the formation of at least five different products, their identities could not be properly determined, except for the easily recognisable imidazolium salt 1-pyridyl-3-mesitylimidazolium azide. Monitoring the photolysis by IR spectroscopy (Fig. 7), however, gave a better understanding of the processes occurring. The final trace shows the presence of two pairs of carbonyl peaks at 1938, $1866 \mathrm{~cm}^{-1}$ and 1916, $1833 \mathrm{~cm}^{-1}$, the latter pair being of much higher intensity. The bands at 1938, $1866 \mathrm{~cm}^{-1}$, however, only began to form after 3 hours photolysis. Residual peaks of lower intensity are also observed at 2036 and $2017 \mathrm{~cm}^{-1}$. From comparison to our earlier reports of similar complexes with halide ligands instead of azide, the IR profile of photolysed 2a allows us to assign all of the photoproducts. ${ }^{14}$ The signals at 1916 and $1833 \mathrm{~cm}^{-1}$ are consistent with the formation of 


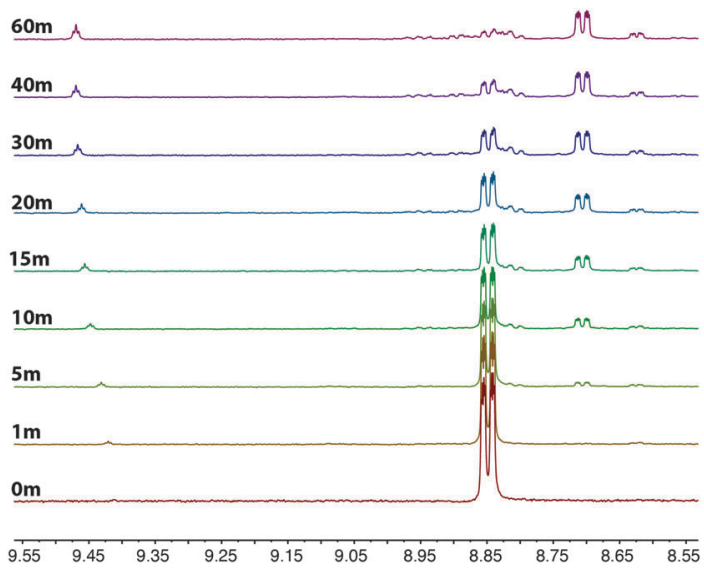

Fig. $6{ }^{1} \mathrm{H}$ NMR progression of the photolysis of $2 \mathrm{a}$ in a deuterated acetonitrile solution. The photolysis was performed by irradiating the sample at $365 \mathrm{~nm}$ over a period of $1 \mathrm{~h}$.

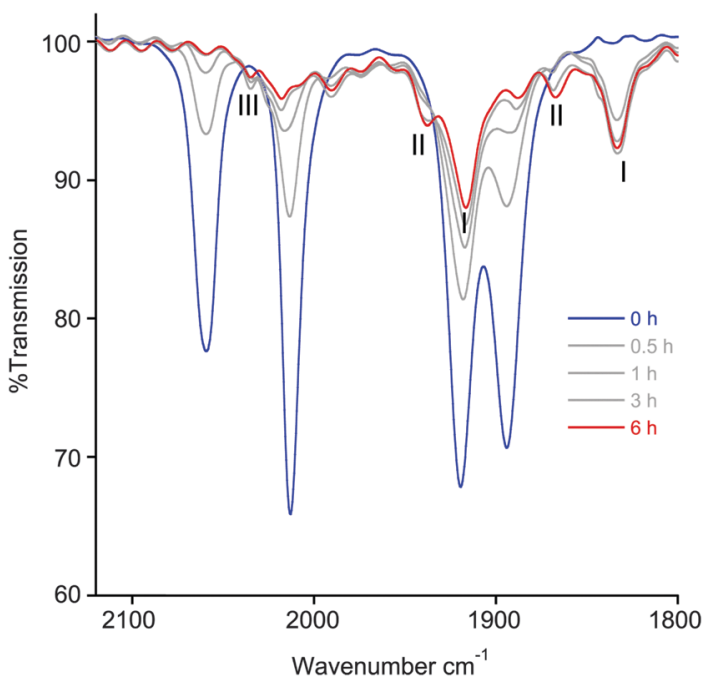

Fig. 7 IR progression of the photolysis of $\mathbf{2} \mathbf{a}$ in an acetonitrile solution. The photolysis was performed by irradiating the sample at $365 \mathrm{~nm}$ over a period of $6 \mathrm{~h}$. For clarity, all traces except the first and last have been drawn in grey.

the neutral complex $\left[\mathrm{Re}(\mathrm{NHC})(\mathrm{CO})_{2}\left(\mathrm{CH}_{3} \mathrm{CN}\right) \mathrm{N}_{3}\right](\mathbf{I})$, while the smaller pair of carbonyl bands are assigned to $\left[\mathrm{Re}(\mathrm{NHC})(\mathrm{CO})_{2^{-}}\right.$ $\left.\left(\mathrm{CH}_{3} \mathrm{CN}\right)_{2}\right] \mathrm{N}_{3}$ (II). Interestingly, and in contrast to the photochemistry of our previously reported rhenium NHC complexes, the neutral species (I) is the major product formed by photolysis, while the ionic complex (II) is only formed in very small amounts. Close examination of the band at $2036 \mathrm{~cm}^{-1}$ shows that the intensity grows up to 3 hours and then decreases. This is consistent with the formation of the intermediate $\left[\mathrm{Re}(\mathrm{NHC})(\mathrm{CO})_{3}\left(\mathrm{CH}_{3} \mathrm{CN}\right)\right] \mathrm{N}_{3}$ (III), which is itself consumed in the formation of (II). Indeed, this band is located at the same wavenumber as the $\left[\mathrm{Re}\left(\mathrm{NHC}^{\mathrm{Ph}}\right)(\mathrm{CO})_{3}-\right.$ $\left.\left(\mathrm{CH}_{3} \mathrm{CN}\right)\right] \mathrm{Cl}$, where the NHC ligand contains a phenyl substituent instead of mesityl.

The absorption and emission profiles of $2 \mathbf{a}$ were measured prior to and after exhaustive photolysis, and are shown in Fig. 8. Significant changes have occurred in the absorption
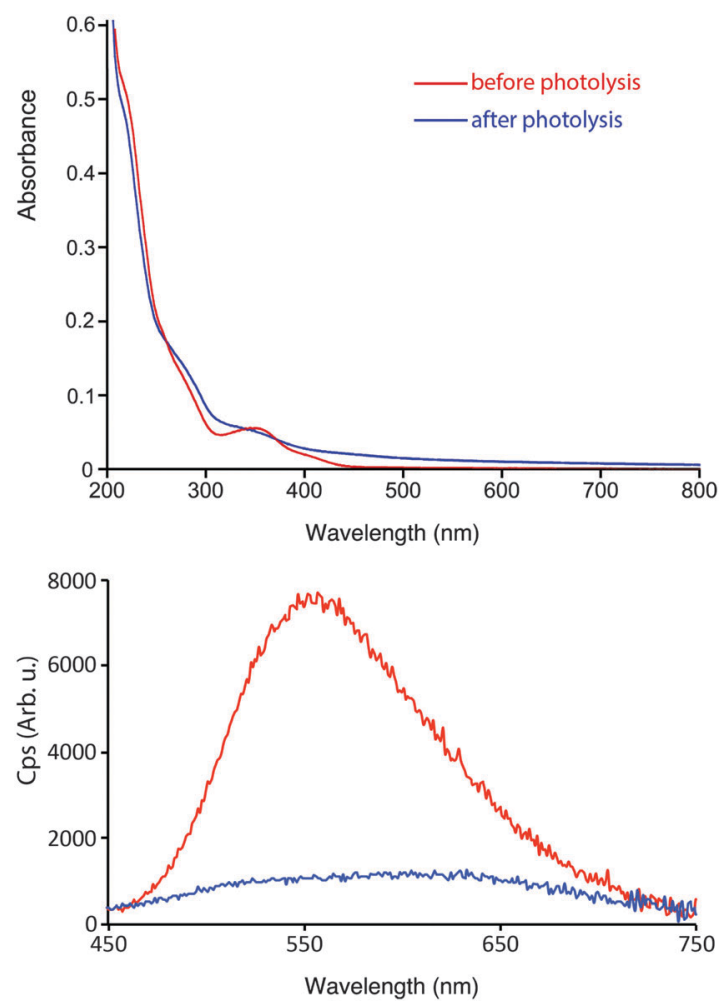

Fig. 8 Experimental absorption (top) and emission (bottom) profiles of $2 \mathbf{a}$ from dilute acetonitrile solutions (ca. $10^{-5} \mathrm{M}$ ) at room temperature before and after exhaustive photolysis. The emission profiles were obtained by exciting the complex at $350 \mathrm{~nm}$. The same colour coding is used between the absorption and emission profiles.

spectra after photolysis, with a loss of the defined MLCT/LLCT band and an increase in the absorbance above $400 \mathrm{~nm}$. The emission spectra shows an initial band centred at $557 \mathrm{~nm}$ followed by large drop in the emission intensity upon photolysis consistent with the photo decomposition of $2 \mathbf{a}$, and the formation of a broad and structureless band that is slightly red-shifted. A red-shifted band of lowered emission intensity is in agreement with the proposed formation of $\left[\mathrm{Re}(\mathrm{NHC})(\mathrm{CO})_{2}\left(\mathrm{CD}_{3} \mathrm{CN}\right) \mathrm{N}_{3}\right](\mathbf{I})$, where the HOMO is raised $c f$. 2a due to the loss of one $\pi$-acidic carbonyl ligand.

The combination of the NMR, IR, absorption, and emission spectra allow the photochemistry of $2 \mathrm{a}$ in $\mathrm{CH}_{3} \mathrm{CN}$ to be explained, and is shown in Scheme 2. After one minute photolysis, 2a begins to decompose to the imidazolium salt, seen as peaks in the in the ${ }^{1} \mathrm{H}$ NMR spectra at 8.63 and $9.44 \mathrm{ppm}$. This observation warrant special mention, for although this side reaction proceeds steadily throughout the course of the photolysis, the formation of the imidazolium salt in this way does not seem consistent with a species that might form via the lowest MLCT excited state. As seen in Fig. 6, however, the imidazolium salt is clearly the first photoproduct formed, in a pathway independent of I-III. This is followed by the observance of (I) and (III) after only five minutes at 8.71 and $8.81 \mathrm{ppm}$, respectively, the former becoming the major species by 10 minutes of irradiation. As the photolysis proceeds (see Fig. 5 and 7), (I) continues to grow; the concentration of (III) remains low and 


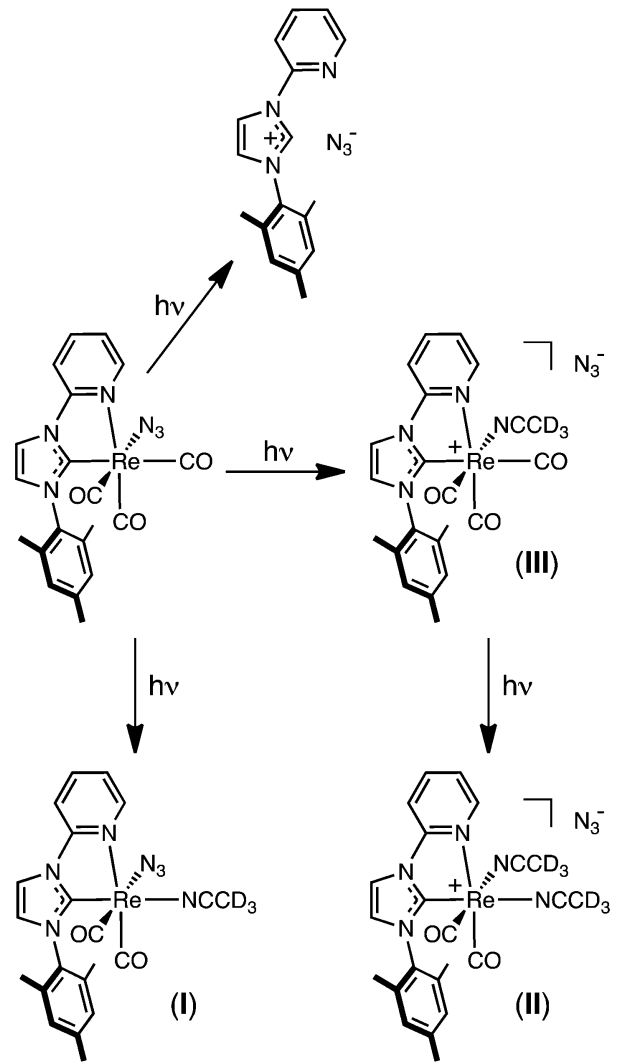

Scheme 2 Reaction pathway describing the photochemical transformation of $2 a$ when excited to their MLCT/LLCT manifold at $\lambda_{\text {ex }}=365 \mathrm{~nm}$.

after three hours the signal decreases to zero by $c a$. six hours irradiation. The decrease in the intensity of (III) is associated with the formation of a peak at $8.85 \mathrm{ppm}$ due to complex (II), which is assumed to form via the substitution the carbonyl ligand by acetonitrile trans to the carbene.

The photoreactivity of $\mathbf{3 a}$ as a solution in $\mathrm{CD}_{3} \mathrm{CN}$ was also assessed via ${ }^{1} \mathrm{H}$ NMR spectroscopy, the resulting spectra summarised in Fig. 9. Compared to $2 \mathbf{a}$, the reactivity of $3 \mathbf{a}$ upon irradiation was markedly slower, with no photoproducts being observed in the first two hours of the experiment. Examination of the $\mathrm{N}^{\prime}{ }^{\prime}$ signal in the ${ }^{1} \mathrm{H}$ NMR spectrum of $\mathbf{3 a}$ shows the presence of the $\mathrm{N}(2)$ and $\mathrm{N}(1)$ bound triazolate again in the ratio of $1: 0.18$, however this ratio increased over the 13 hours of irradiation. The exact amount of N(1) bound triazolate, however, could not be determined due the appearance of an unidentified species at $8.69 \mathrm{ppm}$ that partially overlapped the signal. In a similar fashion to the photolysis of $2 a$, signals at $8.63 \mathrm{ppm}$ due to an imidazolium salt formed after two hours and continued to increase in concentration during the experiment. It is not clear whether the counteranion of the imidazolium salt would be the triazolate or a triazolate-derived decomposition product. Monitoring the photolysis by IR spectroscopy reveals little change over 6 hours, with the exception of two small bands being formed at 1867 and $1845 \mathrm{~cm}^{-1}$. These bands may be attributed to the formation of a dicarbonyl complex, although we are uncertain at present of its identity. Still it seems likely that one or more

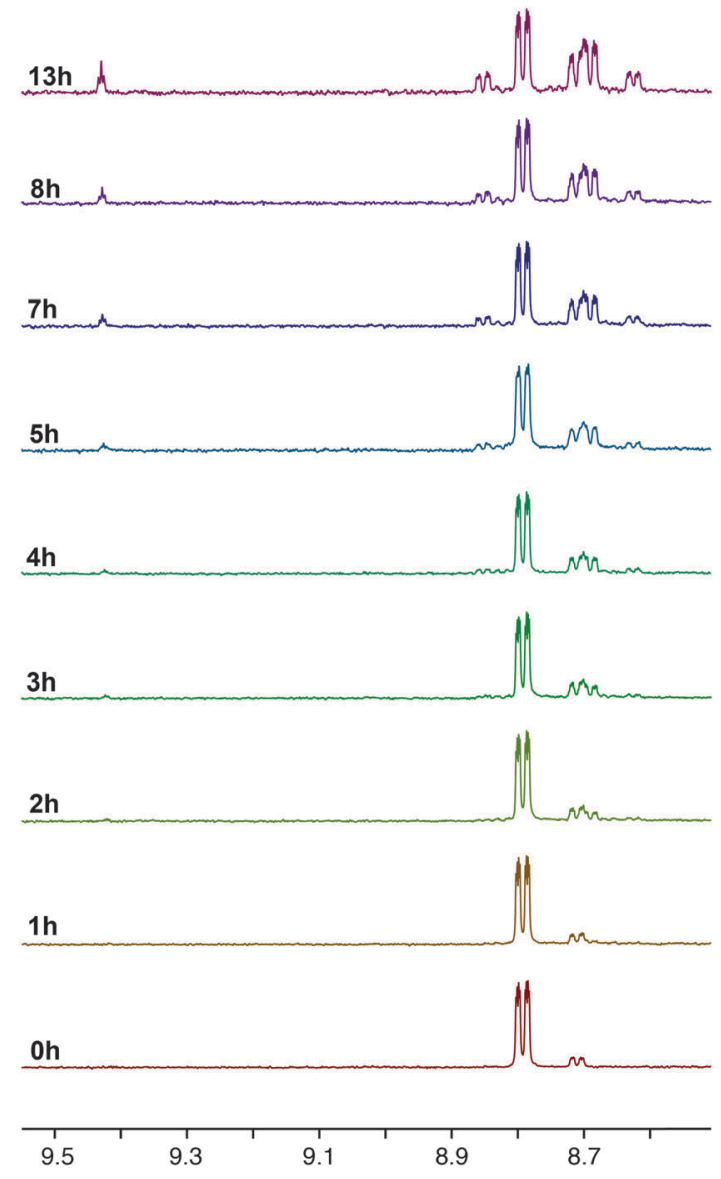

Fig. $9{ }^{1} \mathrm{H}$ NMR progression of the photolysis of $3 \mathrm{a}$ in deuterated acetonitrile solutions. The photolysis was performed by irradiating the sample at $365 \mathrm{~nm}$ over a period of $13 \mathrm{~h}$.

dicarbonyl species are formed, given the number of species observed in the ${ }^{1} \mathrm{H}$ NMR. In an attempt to monitor the emission of $3 \mathrm{a}$ during photolysis, a $\mathrm{CH}_{3} \mathrm{CN}$ solution of the complex (ca. $10^{5} \mathrm{M}$ ) was exposed to prolonged excitation inside the fluorimeter, but only a minor decrease in the emission intensity and no noticeable shift in the wavelength of emission, was observed.

\section{Conclusion}

The synthesis of the first rhenium(I) N-heterocyclic carbene complexes containing azide ligands (2a and $\mathbf{2 b}$ ) has been performed, with the subsequent cycloaddition reaction with model alkyne dimethyl acetylenedicarboxylate affording triazolate ligated complexes $\mathbf{3} \mathbf{a}$ and $\mathbf{3} \mathbf{b}$. The photophysical properties of the compounds have been investigated, and revealed a dependence on both the heterocyle bound to the imidazole (pyridyl vs. pyrimidyl) and the auxiliary ligand (azide vs. triazolate). The complexes display phosphorescent decay from triplet charge transfer (metal-to-ligand and ligand-to-ligand) excited states with markedly different $\lambda_{\mathrm{em}}$ and decay lifetimes $(\tau)$. The pyrimidyl group serves to lower the relative energy of the LUMO due to being more electron deficient compared with the pyridyl group, 
while the electron donating nature of the azide raises the HOMO $c f$. the electron withdrawing triazolate. Consistent with previous reports, the complexes with pyridyl substituents on the $\mathrm{N}$-heterocyclic carbene were found to be photoactive when excited into the charge transfer manifold. Although difficult to interpret compared to analogous complexes containing halide ligands, photolysis of 2a revealed three independent pathways: the photodecomposition to the imidazolium salt; formation of the neutral $\left[\mathrm{Re}(\mathrm{NHC})(\mathrm{CO})_{3}\left(\mathrm{CD}_{3} \mathrm{CN}\right) \mathrm{N}_{3}\right](\mathrm{I})$ as the major species; and formation of the tricarbonyl acetonitrile solvate $\left[\mathrm{Re}(\mathrm{NHC})(\mathrm{CO})_{3}\left(\mathrm{CD}_{3} \mathrm{CN}\right)\right] \mathrm{N}_{3}$ (III), which then rapidly reacts to give the dicarbonyl species $\left[\mathrm{Re}(\mathrm{NHC})(\mathrm{CO})_{2}\left(\mathrm{CD}_{3} \mathrm{CN}\right)_{2}\right] \mathrm{N}_{3}$ (II). The photochemistry of 3a was much slower than that of 2a, with significant amounts of starting material still present after 13 hours irradiation. Again, the formation of an imidazolium salt and a general increase in the concentration of the $\mathrm{N}(1)$ bound-isomer was observed, but the other photoproducts have not yet been identified, although dicarbonyl complexes seem likely. The results presented in this paper describe new types of easily accessible rhenium(I) $\mathrm{N}$-heterocyclic carbene complexes that have very different photophysical/photochemical properties to those previously reported. An investigation of the scope of the 1,3-diploar cycloaddition reaction using rhenium(I) N-heterocyclic carbene complexes of azide ligands is currently underway in our group.

\section{Experimental section}

\section{General considerations}

All reagents and solvents were purchased from Sigma Aldrich and used as received without further purification. All reactions were conducted under an atmosphere of $\mathrm{N}_{2}$. All reactions and subsequent manipulations were performed in the dark where possible. Complexes $\mathbf{1 a}$ and $\mathbf{1 b}$ were prepared according to previously published procedures. ${ }^{15}$ Nuclear magnetic resonance spectra were recorded using a Bruker Avance 400 spectrometer (400.1 MHz for ${ }^{1} \mathrm{H} ; 100 \mathrm{MHz}$ for ${ }^{13} \mathrm{C}$ ) at $300 \mathrm{~K}$. All the NMR spectra were calibrated to residual solvent signals. Infrared spectra were recorded using an attenuated total reflectance Perkin Elmer Spectrum 100 FT-IR with a diamond stage. IR spectra were recorded from 4000 to $650 \mathrm{~cm}^{-1}$. The intensities of the IR bands are reported as strong (s), medium (m), or weak (w), with broad (br) bands also specified. Elemental analyses were obtained at Curtin University using a Thermo Finnigan EA 1112 Series Flash.

\section{Photophysical measurements}

Absorption spectra were recorded at room temperature using a Cary 4000 UV/Vis spectrometer. Uncorrected steady state emission and excitation spectra were recorded on an Edinburgh FLSP980-S2S2-stm spectrometer equipped with: (i) a temperaturemonitored cuvette holder; (ii) $450 \mathrm{~W}$ Xenon arc lamp; (iii) double excitation and emission monochromators; (iv) a Peltier cooled Hamamatsu R928P photomultiplier tube (spectral range 200$870 \mathrm{~nm})$. Emission and excitation spectra were corrected for source intensity (lamp and grating) and emission spectral response (detector and grating) by a calibration curve supplied with the instrument. To record the $77 \mathrm{~K}$ luminescence spectra and emission lifetimes, the samples were put in glass tubes ( $2 \mathrm{~mm}$ diameter) and inserted in a special quartz Dewar filled up with liquid nitrogen. According to the approach described by Demas and Crosby, ${ }^{31}$ luminescence quantum yields $\left(\Phi_{\mathrm{em}}\right)$ were measured in optically dilute solutions (O.D. $<0.1$ at excitation wavelength) obtained from absorption spectra on a wavelength scale [nm] and compared to the reference emitter by the following equation:

$$
\Phi_{\mathrm{x}}=\Phi_{\mathrm{r}}\left\lfloor\frac{A_{\mathrm{r}}\left(\lambda_{\mathrm{r}}\right)}{A_{\mathrm{x}}\left(\lambda_{\mathrm{x}}\right)}\right\rfloor\left\lfloor\frac{I_{\mathrm{r}}\left(\lambda_{\mathrm{r}}\right)}{I_{\mathrm{x}}\left(\lambda_{\mathrm{x}}\right)}\right\rfloor\left\lceil\frac{n_{\mathrm{x}}^{2}}{n_{\mathrm{r}}^{2}}\right]\left\lceil\frac{D_{\mathrm{x}}}{D_{\mathrm{r}}}\right\rfloor
$$

where $A$ is the absorbance at the excitation wavelength $(\lambda), I$ is the intensity of the excitation light at the excitation wavelength $(\lambda), n$ is the refractive index of the solvent, $D$ is the integrated intensity of the luminescence and $\Phi$ is the quantum yield. The subscripts $r$ and $x$ refer to the reference and the sample, respectively. The quantum yield determinations were performed at identical excitation wavelength for the sample and the reference. The quantum yields of complexes were measured against an airequilibrated $0.1 \mathrm{M} \mathrm{H}_{2} \mathrm{SO}_{4}$ solution of quinine sulfate $\left(\Phi_{\mathrm{r}}=0.53\right) .{ }^{33}$ Emission lifetimes $(\tau)$ were determined with the time correlated single photon counting technique (TCSPC) with the same Edinburgh FLSP980-S2S2-stm spectrometer using either a pulsed picosecond LED (EPLED/EPL 377 nm, FHWM < 800 ps) or a microsecond flashlamp The goodness of fit was assessed by minimizing the reduced $\chi^{2}$ function and by visual inspection of the weighted residuals. The solvents used for the preparation of the solutions for the photophysical investigations were of LR grade and the water was deionised. Experimental uncertainties are estimated to be $\pm 8 \%$ for lifetime determinations, $\pm 20 \%$ for quantum yields, $\pm 2 \mathrm{~nm}$ and $\pm 5 \mathrm{~nm}$ for absorption and emission peaks, respectively.

\section{Monitored photolysis}

Monitored photolysis experiments were carried out using a Edinburgh FLSP980-S2S2-stm spectrometer. The reagents were added to acetonitrile in order to reach a final concentration of ca. $10^{-5} \mathrm{M}(\sim 3 \mathrm{~mL}$ volume $)$ in a quartz cuvette. The unstirred solutions were irradiated at $\lambda_{\mathrm{ex}}=350 \mathrm{~nm}$ with an excitation slit set to $10 \mathrm{~nm}$ and emission slit to $2.5 \mathrm{~nm}$. A consecutive number of spectra, with no delay between replicates, were run per solution at a speed of $240 \mathrm{~nm} \mathrm{~min}{ }^{-1}$ with the detector set to acquire a signal between 400 and $800 \mathrm{~nm}$ so that the complexes underwent exhaustive photolysis. Under these experimental conditions, the solution was constantly irradiated for a period of approximately 3 hours. The spectra were recorded uncorrected for the detector response.

\section{Lamp photolysis}

Lamp photolysis experiments were carried using a UVP Blak-Ray ${ }^{\circledR}$ B-100AP High Intensity UV lamp with a $100 \mathrm{~W}$ bulb at a single wavelength output of $365 \mathrm{~nm}$. The experiments were performed in the darkness. The reaction vessel consisted of a either a glass NMR tube containing deuterated solution of the complex. 


\section{Numbering of complexes}

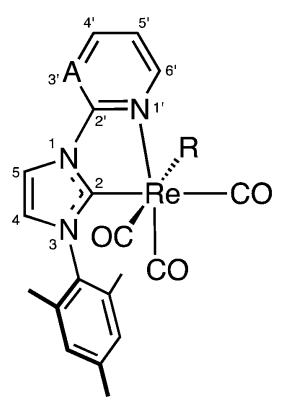

fac- $\left[\operatorname{Re}(\mathbf{C O})_{3}\left(\mathbf{N H C}^{\text {pyridyl }}\right) \mathbf{N}_{3}\right]$ (2a). Silver triflate (70 $\mathrm{mg}$, $0.27 \mathrm{mmol})$ was added to a solution of $1 \mathrm{a}(103 \mathrm{mg}, 0.18 \mathrm{mmol})$ in acetone $(15 \mathrm{~mL})$ and the resulting solution was heated at reflux for $3 \mathrm{~h}$. The mixture was cooled, and then filtered under $\mathrm{N}_{2}$ via cannula filtration into another Schlenk flask. Sodium azide $(118 \mathrm{mg}, 1.81 \mathrm{mmol})$ was added and the mixture was stirred at room temperature overnight. The resulting solution was decanted and the solvent removed under reduced pressure at room temperature. The resulting residue was dissolved in dichloromethane and filtered through a plug of acidic alumina (BII), eluting with dichloromethane $(\sim 200 \mathrm{~mL})$ and then dried under reduced pressure. The residue was dissolved in a mixture of dichloromethane/acetone $(1: 1,5 \mathrm{~mL})$ and then precipitated with pentane. The resulting solid was collected, washed with pentane $(4 \times 3 \mathrm{~mL})$, and dried to afford the product as a yellow solid. Yield: $61 \mathrm{mg}, 59 \%$. Anal. calc. for $\mathrm{C}_{20} \mathrm{H}_{17} \mathrm{~N}_{6} \mathrm{O}_{3}$ Re $\cdot\left(0.15 \mathrm{CH}_{2} \mathrm{Cl}_{2}\right)$ : C 41.14, H 2.96, N 14.28; found: C 41.37, H 2.50, N 13.89. FT-IR (ATR) $\nu_{\max } / \mathrm{cm}^{-1}: 2047 \mathrm{~s}\left(\mathrm{~N}_{3}\right), 2010 \mathrm{~s}(\mathrm{CO}), 1916 \mathrm{~s}(\mathrm{CO}), 1869 \mathrm{~s}(\mathrm{CO})$, $1616 \mathrm{~m}, 1489 \mathrm{~s}, 1455 \mathrm{~m}, 1320 \mathrm{w}, 1263 \mathrm{w} .{ }^{1} \mathrm{H}-\mathrm{NMR} \delta / \mathrm{ppm}$ (acetone$\left.\mathrm{d}_{6}\right): 8.95\left(1 \mathrm{H}, \mathrm{ddd},{ }^{3} J_{\mathrm{H}, \mathrm{H}}=5.6 \mathrm{~Hz},{ }^{4} J_{\mathrm{H}, \mathrm{H}}=1.6 \mathrm{~Hz},{ }^{5} J_{\mathrm{H}, \mathrm{H}}=0.8 \mathrm{~Hz}, \mathrm{H}^{\prime}\right)$, $8.54\left(1 \mathrm{H}, \mathrm{d},{ }^{3} J_{\mathrm{H}, \mathrm{H}}=2.1 \mathrm{~Hz}, \mathrm{H} 4\right), 8.39\left(1 \mathrm{H}, \mathrm{ddd},{ }^{3} J_{\mathrm{H}, \mathrm{H}}=9.0 \mathrm{~Hz},{ }^{3} J_{\mathrm{H}, \mathrm{H}}=\right.$ $\left.7.5 \mathrm{~Hz},{ }^{4} J_{\mathrm{H}, \mathrm{H}}=1.6 \mathrm{~Hz}, \mathrm{H} 4^{\prime}\right), 8.31\left(1 \mathrm{H}, \mathrm{ddd},{ }^{3} J_{\mathrm{H}, \mathrm{H}}=9.0 \mathrm{~Hz},{ }^{4} J_{\mathrm{H}, \mathrm{H}}=\right.$ $\left.1.3 \mathrm{~Hz},{ }^{5} J_{\mathrm{H}, \mathrm{H}}=0.8 \mathrm{~Hz}, \mathrm{H} 3^{\prime}\right), 7.63\left(1 \mathrm{H}, \mathrm{ddd},{ }^{3} J_{\mathrm{H}, \mathrm{H}}=7.5 \mathrm{~Hz},{ }^{3} J_{\mathrm{H}, \mathrm{H}}=\right.$ $\left.5.6 \mathrm{~Hz},{ }^{4} J_{\mathrm{H}, \mathrm{H}}=1.3 \mathrm{~Hz}, \mathrm{H} 4^{\prime}\right), 7.50\left(1 \mathrm{H}, \mathrm{d},{ }^{3} J_{\mathrm{H}, \mathrm{H}}=2.1 \mathrm{~Hz}, \mathrm{H}^{\prime}\right), 7.11$ $(2 \times 1 \mathrm{H}, 2 \times \mathrm{s}, 2 \times$ mesityl CH$), 2.36\left(3 \mathrm{H}, \mathrm{s}\right.$, mesityl $\left.\mathrm{CH}_{3}\right), 2.18(3 \mathrm{H}$, $\mathrm{s}$, mesityl $\left.\mathrm{CH}_{3}\right), 2.14\left(3 \mathrm{H}\right.$, s, mesityl $\left.\mathrm{CH}_{3}\right) .{ }^{13} \mathrm{C}-\mathrm{NMR} \delta / \mathrm{ppm}$ (acetone$\mathrm{d}_{6}$ ): 198.98 (CO), 196.18 (CO), 193.98 (C2), 192.19 (CO), 154.4 (C6'), 140.6 (mesityl quat. C), 143.0 (C4'), 136.7 (mesityl quat. $\mathrm{CH}$ ), 136.4 (mesityl quat. $\mathrm{CH}$ ), 135.6 (mesityl quat. $\mathrm{CH}$ ), 130.2 (mesityl $\mathrm{CH}$ ), 129.9 (mesityl CH), 129.5 (C5), 125.1 (C5'), 118.8 (C4), 113.8 (C3'), 21.2 (mesityl $\mathrm{CH}_{3}$ ), 17.8 (mesityl $\mathrm{CH}_{3}$ ), 17.6 (mesityl $\mathrm{CH}_{3}$ ), $\mathrm{C2}^{\prime}$ was not observed. Crystals of $2 \mathrm{a}$ suitable for X-ray diffraction studies were grown by the diffusion of vapours between pentane and a methanol/acetone/dichloromethane solution of the complex.

fac- $\left[\operatorname{Re}(\mathbf{C O})_{3}\left(\mathbf{N H C}^{\text {pyrmidyl }}\right) \mathbf{N}_{3}\right]$ (2b). Silver triflate $(60 \mathrm{mg}$, $0.23 \mathrm{mmol})$ was added to a solution of $1 \mathrm{a}(63.5 \mathrm{mg}, 0.10 \mathrm{mmol})$ in acetone $(10 \mathrm{~mL})$ and the resulting solution was heated at reflux for $3.5 \mathrm{~h}$. The mixture was cooled, and then filtered under $\mathrm{N}_{2}$ via cannula filtration into another Schlenk flask. Sodium azide $(72 \mathrm{mg}, 1.11 \mathrm{mmol}$ ) was added and the mixture was stirred at room temperature overnight then at reflux for $1.5 \mathrm{~h}$. The resulting solution was decanted and the solvent removed under reduced pressure at room temperature. The resulting residue was dissolved in dichloromethane and filtered through a plug of acidic alumina (BII), eluting with dichloromethane $(\sim 200 \mathrm{~mL})$ and then dried under reduced pressure. The residue was dissolved in acetone $(2 \mathrm{~mL})$ and filtered through a plug of Celite into stirring pentane $(20 \mathrm{~mL})$. The resulting solid was collected, washed with pentane $(4 \times 3 \mathrm{~mL})$, and dried to afford the product as a yellow solid. Yield: $39.3 \mathrm{mg}, 68 \%$. Anal. calc. for $\mathrm{C}_{19} \mathrm{H}_{16} \mathrm{~N}_{7} \mathrm{O}_{3} \mathrm{Re} \cdot\left(0.30 \mathrm{C}_{3} \mathrm{H}_{6} \mathrm{O}\right)$ : C 39.6, H 2.97, N 16.24; found: $\mathrm{C}$

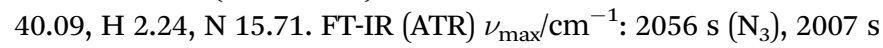
(CO), 1889 br s (CO), $1712 \mathrm{w}, 1595$ s, $1566 \mathrm{w}, 1468$ s, 1378 m. ${ }^{1} \mathrm{H}-\mathrm{NMR} \delta / \mathrm{ppm}$ (acetone-d $\left.\mathrm{d}_{6}\right): 9.30\left(1 \mathrm{H}, \mathrm{dd},{ }^{3} J_{\mathrm{H}, \mathrm{H}}=5.6 \mathrm{~Hz},{ }^{4} J_{\mathrm{H}, \mathrm{H}}=\right.$ $\left.2.2 \mathrm{~Hz}, \mathrm{H}^{\prime}{ }^{\text {or }} \mathrm{H6}^{\prime}\right), 9.19\left(1 \mathrm{H}, \mathrm{dd},{ }^{3} J_{\mathrm{H}, \mathrm{H}}=4.8 \mathrm{~Hz},{ }^{4} J_{\mathrm{H}, \mathrm{H}}=2.2 \mathrm{~Hz}, \mathrm{H}^{\prime}\right.$ or $\left.\mathrm{H6}^{\prime}\right), 8.36\left(1 \mathrm{H}, \mathrm{d},{ }^{3} J_{\mathrm{H}, \mathrm{H}}=2.2 \mathrm{~Hz}, \mathrm{H} 4\right), 7.76\left(1 \mathrm{H}, \mathrm{dd},{ }^{3} J_{\mathrm{H}, \mathrm{H}}=\right.$ $\left.5.6 \mathrm{~Hz},{ }^{3} J_{\mathrm{H}, \mathrm{H}}=4.8 \mathrm{~Hz}, \mathrm{H}^{\prime}\right), 7.60\left(1 \mathrm{H}, \mathrm{d},{ }^{3} J_{\mathrm{H}, \mathrm{H}}=2.2 \mathrm{~Hz}, \mathrm{H} 5\right), 7.12$ $(2 \times 1 \mathrm{H}, 2 \times \mathrm{s}, 2 \times$ mesityl $\mathrm{CH}), 2.36\left(3 \mathrm{H}, \mathrm{s}\right.$, mesityl $\left.\mathrm{CH}_{3}\right), 2.18$ $\left(3 \mathrm{H}, \mathrm{s}\right.$, mesityl $\left.\mathrm{CH}_{3}\right), 2.15\left(3 \mathrm{H}\right.$, s, mesityl $\left.\mathrm{CH}_{3}\right) .{ }^{13} \mathrm{C}-\mathrm{NMR} \delta / \mathrm{ppm}$ (acetone-d $\mathrm{d}_{6}$ ): 198.3 (CO), 195.9 (CO), 193.3 (C2), 191.5 (CO), 163.7 $\left(\mathrm{C} 4^{\prime}\right.$ or $\left.\mathrm{C6}^{\prime}\right), 162.0\left(\mathrm{C}^{\prime}{ }^{\prime}\right.$ or $\left.\mathrm{C6}^{\prime}\right), 159.6\left(\mathrm{C}^{\prime}\right), 140.7$ (mesityl quat. C), 136.7 (mesityl quat. C), 136.0 (mesityl quat. C), 130.2 (mesityl CH), 129.9 (mesityl CH), 125.8 (C5), 121.8 (C5'), 119.4 (C4), 21.2 (mesityl $\mathrm{CH}_{3}$ ), 17.8 (mesityl $\mathrm{CH}_{3}$ ), 17.6 (mesityl $\mathrm{CH}_{3}$ ). Crystals of $2 \mathbf{b}$ suitable for X-ray diffraction studies were grown by layering pentane on top of a dichloromethane solution of the complex and sealing the vial for several days.

fac $-\left[\operatorname{Re}(\mathbf{C O})_{3}\left(\mathbf{N H C}^{\text {pyridyl }}\right)(\right.$ triazolate $\left.)\right]$ (3a). Dimethyl acetylenedicarboxylate $(19 \mu \mathrm{L}, 0.16 \mathrm{mmol})$ was added to a solution of $2 \mathrm{a}(26 \mathrm{mg}, 0.045 \mathrm{mmol})$ in acetone $(5 \mathrm{~mL})$, and stirred at room temperature overnight. The solution was concentrated to $0.5 \mathrm{~mL}$ and filtered through a plug of Celite into stirring pentane $(10 \mathrm{~mL})$. The resulting precipitate was collected, washed with pentane $(4 \times 2 \mathrm{~mL})$, diethyl ether $(3 \mathrm{~mL})$, and dried to afford the product as an off-white solid. Yield: $17 \mathrm{mg}$, $52 \%$. Anal. calc. for $\mathrm{C}_{26} \mathrm{H}_{23} \mathrm{~N}_{6} \mathrm{O}_{7} \mathrm{Re} \cdot\left(0.15 \mathrm{CH}_{2} \mathrm{Cl}_{2}\right): \mathrm{C} 43.00, \mathrm{H}$ 3.22, N 11.51; found: $\mathrm{C} 43.29, \mathrm{H}$ 2.73, N 11.01. FT-IR (ATR) $\nu_{\max } / \mathrm{cm}^{-1}: 2019 \mathrm{~s}(\mathrm{CO}), 1923 \mathrm{~s}$ (CO), $1905 \mathrm{~s}$ (CO), $1740 \mathrm{~m}, 1721$ $\mathrm{s}, 1487 \mathrm{~m}, 1444 \mathrm{w}, 1321 \mathrm{~m}$. Major isomer: ${ }^{1} \mathrm{H}-\mathrm{NMR} \delta / \mathrm{ppm}$ $\left(\mathrm{DMSO}_{6}\right): 8.86\left(1 \mathrm{H}, \mathrm{d},{ }^{3} J_{\mathrm{H}, \mathrm{H}}=5.5 \mathrm{~Hz}, \mathrm{H6}^{\prime}\right), 8.79\left(1 \mathrm{H}, \mathrm{d},{ }^{3} J_{\mathrm{H}, \mathrm{H}}=\right.$ $2.2 \mathrm{~Hz}, \mathrm{H} 4), 8.35-8.51\left(2 \times 1 \mathrm{H}, 2 \times \mathrm{m}, \mathrm{H}^{\prime}{ }^{\prime}\right.$ and $\left.\mathrm{H} 4^{\prime}\right), 7.78(1 \mathrm{H}, \mathrm{d}$, $\left.{ }^{3} J_{\mathrm{H}, \mathrm{H}}=2.2 \mathrm{~Hz}, \mathrm{H} 5\right), 7.52\left(1 \mathrm{H}, \mathrm{ddd},{ }^{3} J_{\mathrm{H}, \mathrm{H}}=6.7 \mathrm{~Hz},{ }^{3} J_{\mathrm{H}, \mathrm{H}}=5.5 \mathrm{~Hz}\right.$, $\left.{ }^{4} J_{\mathrm{H}, \mathrm{H}}=2.0 \mathrm{~Hz}, \mathrm{H}^{\prime}\right), 7.16(1 \mathrm{H}, \mathrm{s}$, mesityl CH), $7.04(1 \mathrm{H}, \mathrm{s}$, mesityl $\mathrm{CH}), 3.70\left(6 \mathrm{H}, \mathrm{s}\right.$, triazolate $\left.\mathrm{CH}_{3}\right), 2.33\left(3 \mathrm{H}, \mathrm{s}\right.$, mesityl $\left.\mathrm{CH}_{3}\right), 2.13$ $\left(3 \mathrm{H}, \mathrm{s}\right.$, mesityl $\left.\mathrm{CH}_{3}\right), 1.56\left(3 \mathrm{H}, \mathrm{s}\right.$, mesityl $\left.\mathrm{CH}_{3}\right) \cdot{ }^{13} \mathrm{C}-\mathrm{NMR} \delta / \mathrm{ppm}$ (DMSO-d 6 ): 198.0 (CO), 195.1 (CO), 193.2 (CO), 191.2 (C2), 162.0 (triazolate COOMe), $153.6\left(\mathrm{C6}^{\prime}\right), 142.6\left(\mathrm{C}^{\prime}\right), 139.0$ (triazolate quat. C), 138.9 (mesityl quat. C), 135.3 (mesityl quat. C), 135.0 (mesityl quat. C), 134.4 (mesityl quat. C), 129.0 (mesityl $\mathrm{CH}$ ), 128.7 (mesityl CH), 125.3 (C5), 125.2 (C5'), 118.4 (C4), 113.0 $\left(\mathrm{C}^{\prime}\right.$ ), 51.6 (triazolate $\mathrm{CH}_{3}$ ), 20.6 (mesityl $\mathrm{CH}_{3}$ ), 17.2 (mesityl $\mathrm{CH}_{3}$ ), 16.2 (mesityl $\mathrm{CH}_{3}$ ), $\mathrm{C2}^{\prime}$ was not observed. Minor isomer: ${ }^{1} \mathrm{H}-\mathrm{NMR} \delta / \mathrm{ppm}\left(\mathrm{DMSO}_{\mathrm{d}}\right): 8.84\left(1 \mathrm{H}, \mathrm{d},{ }^{3} J_{\mathrm{H}, \mathrm{H}}=2.2 \mathrm{~Hz}, \mathrm{H} 4\right) 8.75$ $(1 \mathrm{H}, \mathrm{m}, \mathrm{H} 6), 8.35-8.51\left(2 \times 1 \mathrm{H}, 2 \times \mathrm{m}, \mathrm{H} 3^{\prime}\right.$ and $\left.\mathrm{H} 4^{\prime}\right), 7.76(1 \mathrm{H}$, $\left.\mathrm{d},{ }^{3} J_{\mathrm{H}, \mathrm{H}}=2.2 \mathrm{~Hz}, \mathrm{H} 5\right), 7.50\left(1 \mathrm{H}, \mathrm{m}, \mathrm{H}^{\prime}\right), 7.14(1 \mathrm{H}, \mathrm{s}$, mesityl $\mathrm{CH}), 7.00(1 \mathrm{H}$, s, mesityl $\mathrm{CH}), 3.79\left(6 \mathrm{H}, \mathrm{s}\right.$, triazolate $\left.\mathrm{CH}_{3}\right), 3.71$ $\left(6 \mathrm{H}, \mathrm{s}\right.$, triazolate $\left.\mathrm{CH}_{3}\right), 2.32\left(3 \mathrm{H}, \mathrm{s}\right.$, mesityl $\left.\mathrm{CH}_{3}\right), 2.11(3 \mathrm{H}, \mathrm{s}$, mesityl $\left.\mathrm{CH}_{3}\right), 1.26\left(3 \mathrm{H}, \mathrm{s}\right.$, mesityl $\left.\mathrm{CH}_{3}\right)$. The concentration of the N1-linked triazolate complex (minor isomer) in the sample 
was too low to observe the carbon resonances in the ${ }^{13} \mathrm{C}$ NMR spectrum.

fac $-\left[\operatorname{Re}(\mathrm{CO})_{3}\left(\mathrm{NHC}^{\text {pyrimidyl }}\right)(\right.$ triazolate $\left.)\right](3 \mathrm{~b})$. Dimethyl acetylenedicarboxylate $(24 \mu \mathrm{L}, 0.20 \mathrm{mmol})$ was added to a solution of $2 \mathbf{b}$ $(21 \mathrm{mg}, 0.036 \mathrm{mmol})$ in acetone $(5 \mathrm{~mL})$, and heated at reflux overnight. The solution was concentrated to $0.5 \mathrm{~mL}$ and filtered through a plug of Celite into stirring pentane $(10 \mathrm{~mL})$. The resulting precipitate was collected, washed with pentane $(4 \times 2 \mathrm{~mL})$, diethyl ether $(3 \mathrm{~mL})$, and dried to afford the product as an off-white solid. Yield: $17 \mathrm{mg}, 63 \%$. Anal. calc. for $\mathrm{C}_{25} \mathrm{H}_{22} \mathrm{~N}_{7} \mathrm{O}_{7} \mathrm{Re} \cdot\left(0.1 \mathrm{CH}_{2} \mathrm{Cl}_{2}\right): \mathrm{C}$ 41.78, $\mathrm{H} 3.09, \mathrm{~N} 13.64$; found: C 41.46, H 3.08, N 13.48. FT-IR (ATR) $\nu_{\max } / \mathrm{cm}^{-1}$ : $2018 \mathrm{~s}$ (CO), $1911 \mathrm{~s}$ (CO), $1878 \mathrm{~s}$ (CO), $1740 \mathrm{~m}, 1717 \mathrm{~m}, 1599 \mathrm{w}, 1474 \mathrm{~m}$, 1294 w. Major isomer: ${ }^{1} \mathrm{H}-\mathrm{NMR} \delta / \mathrm{ppm}\left(\mathrm{DMSO}_{\mathrm{C}}\right)$ : 9.19-9.24 $\left(2 \times 1 \mathrm{H}, 2 \times \mathrm{m}, \mathrm{H}^{\prime}{ }^{\prime}\right.$ and $\left.\mathrm{H}^{\prime}\right), 8.52\left(1 \mathrm{H}, \mathrm{d},{ }^{3} J_{\mathrm{H}, \mathrm{H}}=2.2 \mathrm{~Hz}, \mathrm{H} 4\right)$, $7.78\left(1 \mathrm{H}, \mathrm{d},{ }^{3} J_{\mathrm{H}, \mathrm{H}}=2.2 \mathrm{~Hz}, \mathrm{H} 5\right), 7.63\left(1 \mathrm{H}, \mathrm{m}, \mathrm{H} 5^{\prime}\right), 7.17(1 \mathrm{H}, \mathrm{s}$, mesityl $\mathrm{CH}), 7.05(1 \mathrm{H}, \mathrm{s}$, mesityl $\mathrm{CH}), 3.71(3 \mathrm{H}, \mathrm{s}$, triazolate $\left.\mathrm{CH}_{3}\right), 2.34\left(3 \mathrm{H}, \mathrm{s}\right.$, mesityl $\left.\mathrm{CH}_{3}\right), 2.14\left(3 \mathrm{H}\right.$, s, mesityl $\left.\mathrm{CH}_{3}\right), 1.47$ (3H, s, mesityl $\mathrm{CH}_{3}$ ). ${ }^{13} \mathrm{C}-\mathrm{NMR} \delta / \mathrm{ppm}\left(\mathrm{DMSO}_{6} \mathrm{~d}_{6}\right): 197.3$ (CO), 194.7 (CO), 192.5 (CO), 190.6 (C2), $163.2\left(\mathrm{C}^{\prime}\right.$ or $\left.\mathrm{C6}^{\prime}\right), 161.9$ (triazolate COOMe), $161.3\left(\mathrm{C}^{\prime}\right.$ or $\left.\mathrm{C6}^{\prime}\right), 158.6\left(\mathrm{C}^{\prime}\right), 139.1$ (mesityl quat. C), 139.0 (triazolate quat. C), 135.2 (mesityl quat. C), 134.6 (mesityl quat. C), 134.3 (mesityl quat. C), 129.0 (mesityl CH), 128.8 (mesityl CH), 125.5 (C5), 120.9 (C5'), 118.7 (C4), 51.7 (triazolate $\mathrm{CH}_{3}$ ), 20.6 (mesityl $\mathrm{CH}_{3}$ ), 17.2 (mesityl $\mathrm{CH}_{3}$ ), 16.0 (mesityl $\mathrm{CH}_{3}$ ). Minor isomer: ${ }^{1} \mathrm{H}-\mathrm{NMR}$ $\delta / \mathrm{ppm}\left(\mathrm{DMSO}_{\mathrm{d}}\right)$ ) $9.21\left(1 \mathrm{H}, \mathrm{m}, \mathrm{H} 4^{\prime}\right.$ or $\left.\mathrm{H}^{\prime}\right), 9.14(1 \mathrm{H}, \mathrm{dd}$, ${ }^{3} J_{\mathrm{H}, \mathrm{H}}=5.6 \mathrm{~Hz},{ }^{4} J_{\mathrm{H}, \mathrm{H}}=2.1 \mathrm{~Hz}, \mathrm{H} 4^{\prime}$ or $\left.\mathrm{H6}^{\prime}\right), 8.57\left(1 \mathrm{H}, \mathrm{d},{ }^{3} J_{\mathrm{H}, \mathrm{H}}=\right.$ $2.2 \mathrm{~Hz}, \mathrm{H} 4), 7.77\left(1 \mathrm{H}, \mathrm{d},{ }^{3} J_{\mathrm{H}, \mathrm{H}}=2.2 \mathrm{~Hz}, \mathrm{H} 5\right), 7.61\left(1 \mathrm{H}, \mathrm{m}, \mathrm{H}^{\prime}\right)$, $7.15(1 \mathrm{H}, \mathrm{s}$, mesityl $\mathrm{CH}), 7.01(1 \mathrm{H}, \mathrm{s}$, mesityl $\mathrm{CH}), 3.79(3 \mathrm{H}, \mathrm{s}$, triazolate $\left.\mathrm{CH}_{3}\right), 3.72\left(3 \mathrm{H}, \mathrm{s}\right.$, triazolate $\left.\mathrm{CH}_{3}\right), 2.13(3 \mathrm{H}, \mathrm{s}$, mesityl $\mathrm{CH}_{3}$ ), $2.12\left(3 \mathrm{H}, \mathrm{s}\right.$, mesityl $\left.\mathrm{CH}_{3}\right), 1.24$ (3H, s, mesityl $\mathrm{CH}_{3}$ ). The concentration of the N1-linked triazolate complex (minor isomer) in the sample was too low to observe the carbon resonances in the ${ }^{13} \mathrm{C}$ NMR spectrum.

X-ray diffraction analysis. Crystallographic data for the structures were collected at 100(2) K on an Oxford Diffraction Xcalibur fitted with Mo $\mathrm{K} \alpha$ radiation $(\lambda=0.71073 \AA)$ Following analytical absorption corrections and solution by direct methods, the structures were refined against $F^{2}$ with full-matrix leastsquares using the program SHELXL-2014. ${ }^{34}$ Anisotropic displacement parameters were employed for the non-hydrogen atoms. All hydrogen atoms were added at calculated positions and refined by use of a riding model with isotropic displacement parameters based on those of the parent atom.

\section{Crystal data}

2a. Formula: $\mathrm{C}_{20} \mathrm{H}_{17} \mathrm{~N}_{6} \mathrm{O}_{3} \mathrm{Re}, M=$ 575.59. Triclinic, space group $P \overline{1}, a=7.5348(5), b=8.5333(4), c=17.6251(12) \AA$, $\alpha=76.322(5)^{\circ}, \beta=79.285(5)^{\circ}, \gamma=69.702(5)^{\circ}, V=1025.99(12)$ $\AA^{3}, Z=2, D_{\text {calc }}=1.863 \mathrm{Mg} \mathrm{m}^{-3}, \mu=5.956 \mathrm{~mm}^{-1}, 2 \theta_{\max }=58^{\circ}$, crystal size $=0.39 \times 0.10 \times 0.04 \mathrm{~mm}^{3}$. Reflections collected $=$ 13846 , unique $=5460, R_{\text {int }}=0.0327$. Data $/$ restraints $/$ parameters $=$ $5460 / 42 / 352$, GooF $=1.125$. Final $R$ indices $(I>2 \sigma(I))$ : $R_{1}=0.0310, \mathrm{w} R_{2}=0.0718 . R$ indices (all data): $R_{1}=0.0344$,

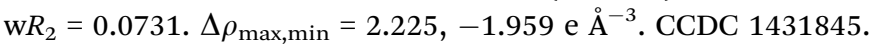

The atoms of the mesityl group were modelled as being disordered over two sets of sites with occupancies constrained to 0.5 after trial refinement with geometries restrained to ideal values.

2b. Formula: $\mathrm{C}_{19} \mathrm{H}_{16} \mathrm{~N}_{7} \mathrm{O}_{3} \mathrm{Re} \cdot 0.69\left(\mathrm{CH}_{2} \mathrm{Cl}_{2}\right), M=634.82$. Triclinic, space group $P \overline{1}, a=7.7716(2), b=11.1256(3), c=15.1208(3) \AA$, $\alpha=81.412(2)^{\circ}, \beta=77.239(2)^{\circ}, \gamma=75.665(2)^{\circ}, V=1229.20(5) \AA^{3}, Z=2$, $D_{\text {calc }}=1.715 \mathrm{Mg} \mathrm{m}^{-3}, \mu=5.125 \mathrm{~mm}^{-1}, 2 \theta_{\max }=54^{\circ}$, crystal size $=$ $0.50 \times 0.20 \times 0.09 \mathrm{~mm}^{3}$. Reflections collected $=24551$, unique $=$ 5344, $R_{\text {int }}=0.0300$. Data/restraints/parameters $=5344 / 12 / 316$, GooF $=1.121$. Final $R$ indices $(I>2 \sigma(I)): R_{1}=0.0341, \mathrm{w} R_{2}=$ 0.0922. $R$ indices (all data): $R_{1}=0.0350, \mathrm{w} R_{2}=0.0929 . \Delta \rho_{\max , \min }=$

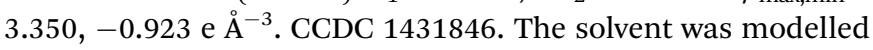
as dichloromethane disordered over two sets of sites with occupancies refined to $0.408(8)$ and $0.279(7)$. Geometries were restrained to ideal values.

3a. Formula: $\mathrm{C}_{26} \mathrm{H}_{23} \mathrm{~N}_{6} \mathrm{O}_{7} \mathrm{Re}, M=717.70$. Monoclinic, space group $P 2_{1} / n, a=11.3508(2), b=14.0357(2), c=16.9573(2) \AA$, $\beta=105.980(2)^{\circ}, V=2597.18(7) \AA^{3}, Z=4, D_{\text {calc }}=1.835 \mathrm{Mg} \mathrm{m}^{-3}$, $\mu=4.737 \mathrm{~mm}^{-1}, 2 \theta_{\max }=64^{\circ}$, crystal size $=0.21 \times 0.06 \times$ $0.04 \mathrm{~mm}^{3}$. Reflections collected $=53533$, unique $=8703, R_{\text {int }}=$ 0.0533. Data/restraints/parameters $=8703 / 0 / 366, \mathrm{GooF}=1.086$. Final $R$ indices $(I>2 \sigma(I)): R_{1}=0.0326, \mathrm{w} R_{2}=0.0572 . R$ indices (all data): $R_{1}=0.0469, \mathrm{w}_{2}=0.0610 . \Delta \rho_{\text {max }, \min }=1.355$, -1.154 e $\AA^{-3}$. CCDC 1431847.

3b. Formula: $\mathrm{C}_{25} \mathrm{H}_{22} \mathrm{~N}_{7} \mathrm{O}_{7} \mathrm{Re}, M=718.69$. Monoclinic, space group $P 2_{1} / c, a=10.6216(2), b=11.42870(10), c=21.8647(3) \AA$, $\beta=95.1090(10)^{\circ}, V=2643.64(7) \AA^{3}, Z=4, D_{\text {calc }}=1.806 \mathrm{Mg} \mathrm{m}^{-3}$, $\mu=4.655 \mathrm{~mm}^{-1}, 2 \theta_{\max }=68^{\circ}$, crystal size $=0.41 \times 0.24 \times$ $0.035 \mathrm{~mm}^{3}$. Reflections collected $=73048$, unique $=10783, R_{\mathrm{int}}=$ 0.0450. Data/restraints/parameters $=10783 / 0 / 361$, GooF $=$ 1.052. Final $R$ indices $(I>2 \sigma(I)): R_{1}=0.0275, \mathrm{w} R_{2}=0.0573$. $R$ indices (all data): $R_{1}=0.0362, \mathrm{w} R_{2}=0.0607 . \Delta \rho_{\max , \min }=1.444$,

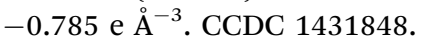

\section{Computational calculations}

Time-dependent density functional theory (TD-DFT) calculations were performed with GAUSSIAN 09 in order to calculate the absorption spectra for synthesized complexes. ${ }^{35}$ Prior to these calculations, the structures were relaxed at the B3LYP level of theory in the presence of an implicit solvent (dichloromethane). The Re atoms were treated with the Stuttgart-Dresden (SDD) effective core potential; ${ }^{36}$ the Pople $6-311++\mathrm{G}^{* *}$ basis set was used for $\mathrm{C}, \mathrm{H}, \mathrm{N}$, and $\mathrm{O}$ atoms, and in all calculations the effect of the solvent was mimicked with the PCM solvation model, ${ }^{37}$ with parameters adequate for dichloromethane. The low-lying singletsinglet excitation energies were calculated at the same level of theory, and the spectra were reproduced as the superposition of Gaussian functions with heights proportional to calculated intensities and a variance of $11 \mathrm{~nm}$.

\section{Acknowledgements}

This work is financially supported by the Australian Research Council (FT130100033 to MM and FT130100463 to PR). 
The authors acknowledge the facilities, and the scientific and technical assistance of the Australian Microscopy \& Microanalysis Research Facility at the Centre for Microscopy, Characterisation \& Analysis, The University of Western Australia, a facility funded by the University, State and Commonwealth Governments. This work was supported by resources provided by the National Computational Infrastructure (NCI), which is supported by the Australian Government.

\section{References}

1 R. A. Kirgan, B. P. Sullivan and D. P. Rillema, Top. Curr. Chem., 2007, 281, 45.

2 A. Vlček Jr, Top. Organomet. Chem., 2010, 29, 73.

3 A. Kumar, S.-S. Sun and A. J. Lees, Top. Organomet. Chem., 2010, 29, 1.

4 M. Mauro, E. Q. Procopio, Y. Sun, C.-H. Chien, D. Donghi, M. Panigati, P. Mercandelli, P. Mussini, G. D'Alfonso and L. De Cola, Adv. Funct. Mater., 2009, 19, 2607.

5 T. Yu, D. P.-K. Tsang, V. K.-M. Au, W. H. Lam, M.-Y. Chan and V. W.-W. Yam, Chem. - Eur. J., 2013, 19, 13418.

6 K. K.-W. Lo, W.-K. Hui, C.-K. Chung, K. H.-K. Tsang, D. C.-M. Ng, N. Zhu and K.-K. Cheung, Coord. Chem. Rev., 2005, 249, 1434.

7 K. K.-W. Lo, K. Y. Zhang and S. P.-Y. Li, Eur. J. Inorg. Chem., 2011, 3551.

8 T. Zou, C. T. Lum, S. S.-Y. Chui and C.-M. Che, Angew. Chem., Int. Ed., 2013, 52, 2930.

9 G. J. Barbante, P. S. Francis, C. F. Hogan, P. R. Kheradmand, D. J. D. Wilson and P. J. Barnard, Inorg. Chem., 2013, 52, 7448.

10 Y. Unger, A. Zeller, S. Ahrens and T. Strassner, Chem. Commun., 2008, 3263.

11 R. Visbal, I. Ospino, J. M. López-de-Luzuriaga, A. Laguna and M. C. Gimeno, J. Am. Chem. Soc., 2013, 135, 4712.

12 C.-H. Yang, J. Beltran, V. Lemaur, J. Cornil, D. Hartmann, W. Sarfert, R. Fröhlich, C. Bizzarri and L. De Cola, Inorg. Chem., 2010, 49, 9891.

13 L. A. Casson, S. Muzzioli, P. Raiteri, B. W. Skelton, S. Stagni, M. Massi and D. H. Brown, Dalton Trans., 2011, 40, 11960.

14 J. G. Vaughan, B. L. Reid, S. Ramchandani, P. J. Wright, S. Muzzioli, B. W. Skelton, P. Raiteri, D. H. Brown, S. Stagni and M. Massi, Dalton Trans., 2013, 42, 14100.

15 J. G. Vaughan, B. L. Reid, P. J. Wright, S. Ramchandani, B. W. Skelton, P. Raiteri, S. Muzzioli, D. H. Brown, S. Stagni and M. Massi, Inorg. Chem., 2014, 53, 3629.

16 X.-W. Li, H.-Y. Li, G.-F. Wang, F. Chen, Y.-Z. Li, X.-T. Chen, Y.-X. Zheng and Z.-L. Xue, Organometallics, 2012, 31, 3829.

17 G.-F. Wang, Y.-Z. Liu, X.-T. Chen, Y.-X. Zheng and Z.-L. Xue, Inorg. Chim. Acta, 2013, 394, 488.

18 S. García-Gallego and G. J. L. Bernardes, Angew. Chem., Int. Ed., 2014, 53, 9712.

19 C. C. Romao, W. A. Blattler, J. D. Seixas and G. J. L. Bernardes, Chem. Soc. Rev., 2012, 41, 3571.
20 U. Schatzschneider, Inorg. Chim. Acta, 2011, 374, 19.

21 U. Schatzschneider, Br. J. Pharmacol., 2015, 172, 1638.

22 T. J. Del Castillo, S. Sarkar, K. A. Abboud and A. S. Veige, Dalton Trans., 2011, 40, 8140.

23 A. R. Powers, I. Ghiviriga, K. A. Abboud and A. S. Veige, Dalton Trans., 2015, 44, 14747.

24 A. R. Powers, X. Yang, T. J. Del Castillo, I. Ghiviriga, K. A. Abboud and A. S. Veige, Dalton Trans., 2013, 42, 14963.

25 X. Yang, S. Wang, I. Ghiviriga, K. A. Abboud and A. S. Veige, Dalton Trans., 2015, 44, 11437.

26 H.-W. Frühauf, Chem. Rev., 1997, 97, 523.

27 L. Henry, C. Schneider, B. Mutzel, P. V. Simpson, C. Nagel, K. Fucke and U. Schatzschneider, Chem. Commun., 2014, 50, 15692.

28 S. D. Koster, H. Alborzinia, S. Can, I. Kitanovic, S. Wolfl, R. Rubbiani, I. Ott, P. Riesterer, A. Prokop, K. Merz and N. Metzler-Nolte, Chem. Sci., 2012, 3, 2062.

29 K. S. Singh, K. A. Kreisel, G. P. A. Yap and M. R. Kollipara, J. Organomet. Chem., 2006, 691, 3509.

30 S. A. Knott, J. N. Templeton, J. L. Durham, A. M. Howard, R. McDonald and L. F. Szczepura, Dalton Trans., 2013, 42, 8132.

31 S. Stagni, S. Colella, A. Palazzi, G. Valenti, S. Zacchini, F. Paolucci, M. Marcaccio, R. Q. Albuquerque and L. De Cola, Inorg. Chem., 2008, 47, 10509.

32 L. Flamigni, A. Barbieri, C. Sabatini, B. Ventura and F. Barigelletti, Top. Curr. Chem., 2007, 281, 143.

33 D. Eaton, Pure Appl. Chem., 1988, 60, 1107.

34 G. M. Sheldrick, Acta Crystallogr., Sect. C: Struct. Chem., 2015, 71, 3.

35 M. J. Frisch, G. W. Trucks, H. B. Schlegel, G. E. Scuseria, M. A. Robb, J. R. Cheeseman, G. Scalmani, V. Barone, B. Mennucci, G. A. Petersson, H. Nakatsuji, M. Caricato, X. Li, H. P. Hratchian, A. F. Izmaylov, J. Bloino, G. Zheng, J. L. Sonnenberg, M. Hada, M. Ehara, K. Toyota, R. Fukuda, J. Hasegawa, M. Ishida, T. Nakajima, Y. Honda, O. Kitao, H. Nakai, T. Vreven, J. A. Montgomery Jr., J. E. Peralta, F. Ogliaro, M. J. Bearpark, J. Heyd, E. N. Brothers, K. N. Kudin, V. N. Staroverov, R. Kobayashi, J. Normand, K. Raghavachari, A. P. Rendell, J. C. Burant, S. S. Iyengar, J. Tomasi, M. Cossi, N. Rega, N. J. Millam, M. Klene, J. E. Knox, J. B. Cross, V. Bakken, C. Adamo, J. Jaramillo, R. Gomperts, R. E. Stratmann, O. Yazyev, A. J. Austin, R. Cammi, C. Pomelli, J. W. Ochterski, R. L. Martin, K. Morokuma, V. G. Zakrzewski, G. A. Voth, P. Salvador, J. J. Dannenberg, S. Dapprich, A. D. Daniels, Ö. Farkas, J. B. Foresman, J. V. Ortiz, J. Cioslowski and D. J. Fox, Gaussian 09, Gaussian, Inc., Wallingford, CT, USA, 2009, vol. revision B.01.

36 D. Andrae, U. Häußermann, M. Dolg, H. Stoll and H. Preuß, Theor. Chim. Acta, 1990, 77, 123.

37 J. Tomasi, B. Mennucci and R. Cammi, Chem. Rev., 2005, $105,2999$. 